\title{
ETNICIDAD Y FORMACIÓN NACIONAL EN AMÉRICA LATINA Y EL CARIBE
}

\author{
Kees Koonings, Patricio Silva, Michiel Baud, Gert Oostindie, \\ Arij Ouweneel *
}

\begin{abstract}
RESUMEN
La relación entre la formación de naciones y la etuicidad en Larinoumérica y el Caribe se casacteriza por una gran ambivalencia. El proceso de formación de naciones en la mayoria de las seciedades latinoameriénos se quedó muy atrás con respecto al proceso de formación de Estados. A menudo se da como explicación la gran heterogeneidad étniea de esa zona. La relación entre la formación de naciones (o estados nacionales) y la cuestión étnica es, sin embargo, mas compleja.

Este articulo utilisa como punto de partida una noción de etnicidad que enfitiza su indole estratégico. El analisis de la importancia de las estrategias étniens para la fomación de naciones en Latinoamérica y el Caribe yue esta articulo propone, pasa por tres dimensiones: formación de Estados, ciudadania e identidad nacional. En primer lugar trataremos sobro los factores que determinaron la formación temp̣rana de Estados en esa región. Llama la aterseiśn tanto la ambivalencia de las clites como el hecho de que soloen contadas ocisiones se dio una resistencia inspirada en la etnia contra la división política establecida. No obstante, las élites a menudo tendieron a imponer tun selloctruco a la resistencia social y politica. A continuación hablaremos de la dimensión ćtnica de la ciudadania, de la participación y de la exclusión. La relación entre la etnicidad y la desigualdad social y política es un tema importante dentro de la formación de naciones con respecto a Latinoumérica y el Caribe. Finalmente intentaremos indicar cómo las estrntegias étnicas influyen (han influido) en el desarrollo de las identidades nacionales de está región.
\end{abstract}

\footnotetext{
- Los autores son académicos que pertenecen a Universidades holandeses. Este articulo es un capitulo revisado de un libro que se publicó en el Ecuador: Esnicidad como Estrategia en America Latina y el Caribe. Quito: Abyn-Yala, 1996.

Kees Koonings, Socislogo. Departamento de Antropologia, Universidad de Ltrecht Patricio Silva, Politicologo. Depatamento de Astropología y Sociologia, Universidad de Leiden Michiel Bazd, Ilistoriador. Departamento de Estudios Litinoamerivanos, Universidad de Leiden Gert Oostindie, Historiador. Departamento de Estudios del Caribe, Real Instituto de Antropologia y Linguistica, Leiden. Departanento de Antropologia, Cniversidad de latrecht

Arij Onweneel, Historiador. Centro de Estudios y Documentación Latinoanerieanos (CEDLA), Ansterdam
} 


\section{INTRODUCCIÓN}

En este articulo se analizará en forma general cl proceso de formación nacional en América Latina y el Caribe desde sus dimensiones étnicas. Para ésto, haremos uso de una conceptualización de etnicidad que privilegia sus caracteristicas estratégicas. Desde esta perspectiva, queremos señalar que la etnicidad, o mejor dicho las relaciones étnicas, pueden ser entendidas como la construcción de diferencias socioculturales en condiciones de competencia, contestación o conflicto. Sin pretender entrar en el debate existente al respecto. queremos sin embargo señalar que la percepción de la étnicidad como 'recurso estratégico' no implica la adopción de una posición netamente instrumentalista. En este sentido, concordamos con Barth (1969) quien ya tiempo atrás sugirió que la construcción de distinciones (boundaries) responde a la competencia por recursos en la cual la identificación énnica se utiliza para fijar una lógica de inclusión o exclusión de ciertos grupos o categorias sociales. Esto implica que se hace uso de elementos de identidad cultural colectiva que van mucho más allá de aquellos de carácter puramente oportunistas que son manejados por líderes intelectuales o politicos. Sin embargo, rechazamos auqella noción de etnicidad que la presenta como una atribución fija e inmutable de ciertos grupos sociales.

El analisis de la importancia de las estrategias étnicas para la formación de naciones en Latinoamérica y el Caribe que csta ponencia propone, pasa por tres dimensiones: formación de Estados, ciudadania e identidad nacional. En primer lugar trataremos sobre los factores que determinaron la formación temprana de Estados en esa región. Llama la atención tanto la ambivalencia de las elites como el hecho de que sólo en contadas ocasiones se dio una resistencia inspirada en la etnia contra la división politica establecida. No obstaute, las élites a menudo tendicron a imponer un sello étnico a la resistencia social y política. A continuación hablaremos de la dimensión étnica de la ciudadania, de la participación y de la exclusión. La relación entre la etnicidad y la desigualdad social y política es un tema importante dentro de la formación de naciones con respecto a Latinoamérica y el Caribe. Finalmente intentaremos indicar cómo las estrategias étnicas influyen (han influido) en el desarrollo de las identidades nacionales de esta región. Se propone una distinción entre paises en los que existe una relativa homogeneidad etnocultural y países en los que hay una gran diversidad étnica y por tanto la formación de una identidad nacional puede plantear problemas. 


\section{FORMACIÓN DE NACIONES Y ETNICIDAD}

¿Qué elementos ocupan un lugar central en el proceso de formación de naciones y qué relación tiene la etnicidad con ese proceso? La formación de naciones supone (ta aspiración a) un territorio limitado, un Estado soberano y la incorporación social y cultural de la población perteneciente a ese Estado. Estudios recientes sobre la formación de naciones y el nacionalismo subrayan la importancia crucial de la institucionalización del Estado moderno. No se considera al Estado como punto final de un largo proceso histórico en el que un pucblo busca reconociniento y autodeterminación políticos. La consolidación política y militar del Estado y el principio juridico de la ciudadanía sólo sentaron las bases para el desarrollo de otras dimensiones de la formación de naciones: la comunidad de intereses civiles y la cultura nacional que se filtra desde arriba en capas amplias de la socicdad.

En este sentido Smith (1986) y Tilly (1990) hacen hincapié en la centralización militar y administrativa del Estado como base de la nación moderna. Otros relacionan este proceso con la expansión de la economía de mercado capitalista y el surgimiento de la división laboral industrial y de la diferenciación social. Sin embargo, sólo la formación de Esıadosy el capitalismo no pueden explicar el surgimiento de las naciones; también deben existir dimensiones suplementarias sociales y culturales. Anderson cita, entre otras, la utilización de los idiomas minoritarios como un elemento importante en la génesis del nacionalismo moderno. Tambićn Hobsbawn (1991) sefiala las raíces prenacionales de la formación de naciones, aunque considera menos importantes el idiona. la religión y la etnicidad. En estas interpretaciones la etnicidad parece influir sólo a posteriori de forma secundaria, o como construcción.

Por el contrario, Suith (1986) sostiene que además del trayecto civil 'clásico' hacia el estado nación también la etnicidad puede constituir la base directa de la formación de naciones. Precisamente en esta segunda ruta se activan las características étnicas (nombre, territorio, idioma, solidaridad mutua, cultura) a fin de crear o reforzar un Estado soberano y de estimular la participación de sus súbditos. En el transcurso del siglo XIX, o bien los Estados, o bien las élites reinantes empezaron a darse cuenta de la ventaja que suponía la 'elnificación' del estado nación. Se fomentó esta ctnificación debido al hecho de que un grupo étnico dominante normalmente organizaba y controlaba tanto el Estado como su jdioma y su cultura oficial. Según Hobsbawm (1991), esta "etrificación' y los fundamentos politicos y culturales para la incorporación o la exclusión. que en principio esta misma hacia posibles, iban relacionados con la necesidad de legitimidad y dominio politico de los grupos sociales considerados como inferiores y amenazadores. 
En América Latina justo después de la independencia, la 'etnificación' del estado nación no fue un objetivo prioritario. Originalmente los estados naciones aspiraban sólo a la consolidación del poder estatal sobre el territorio y consideraban automáticamente a los súbditos libres como ciudadanos, sin tener en cuenta el origen, el idioma, la cultura, la religión o el color de la piel - aunque por supuesto no todos los ciudadanos cran iguales.

Esto nos conduce al segundo elemento de la formación de naciones, que viene después de la ciudadania: la consolidación de una comunidad de intereses de 'ciudadanos'. EI tipo ideal de nación no es sólo una forma juridicoterritorial formal de organización politica, sino también una comunidad con un carácter civil por excelencia. Sin embargo, no todas las sociedades conceden a todos sus súbditos una ciudadania cquivalente. ¿En base a qué criterios se sitúa a categorías de ciudadanos dentro o por el contrario fuera de la sociedad nacional y de la ciudadanía efectiva?

La noción convencional de ciudadanía es en teoría incorporadora: en principio, cada vez a más grupos de la sociedad se les da acoeso a los derechos civiles, politicos y sociales. Sin embargo, la historia denuestra que siempre existen mecanismos de exclusión, basados en clase, posición social, género, edad, origen, etc. También la ennicidad es un motivo tradicional muy importante para la exclusión. Hasta los años sesenta los negros en Estados Unidos no consiguieron la ciudadanía de pleno derecho. En todas las partes del mundo, a los inmigrantes se les excluye de los derechos civiles, políticos y sociales por diferentes motivos. En Latinoamérica y el Caribe a distintas categorias de 'mestizos' o 'indigenas' se les negó la ciudadanía efectiva en el siglo XIX y $\mathrm{XX}$.

En las últimas deccadas se le está dando cada vez más importancia a una 'dimensión cultural' de la ciudadanía. Dentro de una nación se consideran los derechos de las minorias o de los pueblos indigenas como un complemento de la ciudadanía civil, política y social. Este reconocimiento de la diversidad etnocultural puede subordinar la etnicidad como principio regulativo a la nación, sin que ello implique la exclusión de grupos étnicos. Esta es la situación en la sociedad 'ideal' multicultural. Si en el marco de la consolidación y centralización del estado nación sí se da una jerarquización en base a la etnia, esto puede provocar un resurgimiento étnico ('eshnic revival). La homogeneización étnica forzada encontrará resistencia, en caso de que vaya acompañada de la perspectiva de una subordinación social, política y cultural permanente al grupo étnico dominante. En caso de que el reconocimiento de estas dimensiones culturales o étnicas de los derechos civiles se vea frustrado, es posible que tales grupos opten por el nacionalismo étnico separatista. Dicha opción se va haciendo más atractiva a medida que salen a la luz más ejemplos 
de una separación efectiva conseguida por grupos étnicos y reconocida por la comunidad internacional.

La tercera dimensión de la formación de naciones se refiere a la formación de una unidad nacional en el sentido subjetivo: a la nación se le da un significado mayor a medida que crece el sentimiento de identidad nacional. Finalmente la formación de naciones también implica que las naciones se convierten en entidades culturales reconocibles. Se supone que esta dimensión cultural de la identidad nacional, que quizás se puede definir incluso como sociopsicológica, prevalece sobre marcos de referencia colectivos de otro tipo, y es en el caso de una formación de naciones 'exitosa' la principal fuente de colectivisno. En este caso también existen importantes puntos de contacto con la etnicidad y las estrategias étnicas.

A las naciones les gusta definirse como naturales, elernas y únicas; las aspiraciones y los dereclios nacionales se basan en tales nociones y en una 'identidad nacional'. Por eso, estar en 'posesión' de una larga historia colectiva resulta atractivo; en caso de que ésta no exista. esa historia se puede 'inventar'. En este contexto Hobsbawm habla de ingeniería ideológica ('ideological engineering'). Tambićn Anderson y Smith le prestaron mucha atención a la importancia de las construcciones simbólicas que prueban o sugieren una profundidad etnohistórica y una unidad cultural. La más importante de estas construcciones es quizás el 'idioma nacional', aunque tambićn los portadores de significado como mapas geográlicos, muscos, paisajes, léroes, guerras y nociones de 'siglos de oro' contribuyen a cllo. En este sentido, las naciones y las etnias pueden cubrir el mismo terreno, en particular como construcciones de coleclividad e identidad basadas en nombres, historia, idioma, cultura, normas y valores, mitología, simbolismo, etc. Por tanto. la clnicidad y la formación de naciones no sólo se pueden considerar como opciones estratégicas, sino que además se pueden utilizar como prolongación la una de la otra. Así el estado nación civil puede construir con efectos retroactivos un origen étnico. La nación énica homogénea puede servirse de esta característica como punto de partida para la soberania nacional y para la plena incorporación de sus ciudadanos.

\section{3. ¿ESTADOS SIN NACIONES?}

A Simón Bolivar se le atribuye la frase de que una rebclión de castas (pará él en este contexto: negros libres) y esclavos sería 'mil veces peor' que una invasión española. Esta frase ilustra de manera sorprendente el dilema de 
las élites latinoanericanas. Los nuevos Estados soberanos de Latinoamérica originalmente eran 'Estados sin naciones': a grandes partes de la población se les negaban los derechos civiles fundamentales, todavía apenas se podía hablar de una comunidad de intereses civiles y de una identidad o de una cultura nacional. ¿Qué habia ocurrido anteriormente? ¿Influyeron la enicidad o las estrategias étnicas en cl surgimiento del 'protonacionalismo' y en la lucha por la independencia? ¿Posteriormente, de qué manera se concilió la diversidad ctnica con la institucionalización de los nuevos Estados y con la ciudadanía?

La caída de la casa real española causada por Napolcón en 1808 acarré en Hispanoamérica una crisis de legitimidad aguda de las autoridades coloniales. Sin embargo, esta crisis no provocó el surgimiento de un nacionalismo panamericano o la organización de un único Estado federal latinoamericano. Anderson trató de explicar esto con la siguiente hipótesis. La fragmentación territorial de la aduinistración colonial en Latinoamérica y el fucrte carácter local de la prensia 'criolla' finalmente trazaron fronteras muy restringidas de las comunidades imaginadas ('imagined communities') de las élites hispanoamericanas. La patria subjetiva ( $y$ en estos circulos colectiva) no eran unos Estados Unidos de Hispanoamérica, sino la patria chica, el lugar de nacimiento y el linterland. Esto contribuyó a que fracasasen los esfuerzos de Bolivar y de otros por conseguir unas federaciones hispanoamericanas en esa región. Sólo en dos casos se evitó esa fragmentación, y en ambos casos se trató de una monarquia. En México los dirigentes regionales consiguieron instalar unos Estados Unidos de México que en un principio tomaron la forma de un imperio y que resultaron tan atractivos que incluso la provincia guatemalteca de Chiapas se unió a estos Estados (1824). En Brasil, debido al traslado de la corte portuguesa a la colonia brasilena. también se pudo instaurar un imperio centralista e independiente.

Los esfucrzos de la Corona española - y por otra parte también de la Corona portuguesa - por cambiar el desarrollo de los acontecimientos y por restablecer el control debilitado en los territorios de ultramar, tuvieron un efecto contraproducente e intensificaron la lucha de intereses entre las élites criollas y los dirigentes coloniales. Esto desencadenó la 'confusión étnica' que invadió a las élites criollas en los años de la emancipación y que se apoderó de las mismas durante el siglo XIX. Por una parte, estas élites se vieron obligadas a formular una nueva identidad criolla 'americana'. Por otra parte, la élite criolla no estaba dispuesta a renunciar a la posición cómoda de la que había gozado en la sociedad colonial y además todavia le seguia atrayendo mucho la cultura europea. Se la definido acertadamente el miedo de las élites locales a la pérdida de su posición privilegiada como miedo a la revolución. Este miedo no sólo se fundaba en las pretensiones de la madre patria colonial, sino también en las 
pretensiones de las clases y de los grupos étnicos subordinados; las élites dudaban de si las autoridades coloniales serian capaces de reprimir una eventual sublevación de las masas.

Muchos criollos opinaban que ellos mismos debian tomar las riendas y su opinión se vio reforzada por el rumbo dramático que tomó la historia colonial de las Américas: la Revolución de Haiti. En 1791 los esclavos de SaintDomingue, rica colonia de plantación francesa, recurrieron a las armas. Pronto esta lucha se convertiría en un esfuerzo por liberarse de la esclavitud y de deshacerse de las élites y de los grupos de clase media blancos y mestizos. Bajo el mando de Toussaint Louverture, los esclavos, que constituian el $90 \%$ aproximadamente de la población, se sublevaron masivamente. Varias inlervenciones curopeas no pudieron hacer fracasar el éxito de la sublevación de esclavos. En 1804 Haiti, bajo el mando del general negro Dessalines, llegó a ser la segunda república independiente - tras Estados Unidos - en cl hemisferio occidental. La constitución de 1806 declaraba que todos los ciudadanos de Haití eran 'negros', independientemente del color de su piel. La raza para los haitianos era la base de su exigencia de independencia, y la sublevación de esclavos se convirtió en el símbolo (para muchos aterrador) de una guerra de independencia "étnica" y de una revolución social llevadas a cabo con éxito. La Revolución de Haiti se convirtió en una fuente de pánico 'étnico' entre las élites latinoamericanas y caribeñas; el hocho de que la independencia de Cuba se produjera tan tarde se puede atribuir directamente a ello. Asimismo, Haiti fue el primer ejemplo regional de una sociedad étnicamente casi homogénea en la que el origen étnico ocupó un lugar central - a pesar de cierta tendencia a la francotilia entre la ćlite de color más claro - en el simbolismo de la formación de naciones.

Entre las ćlites latinoamericanas del continente sobre todo influyó el uniedo a la población 'india' indigena. La ya citada guerrilla de Thupa Amaro II (1780-1781) en los Andes impresionó mucho a las élites regionales. La amenaza de una sublevación de la población india de repente concienció a los políticos e intelectuales de una posible siluación explosiva debido a la etuia. Quizás incluso resultó más amenazador el hecho de que Thupa Amaro II no se opuso al rey español, sino precisamente a las élites coloniales. Asimismo, en México entre 1810 y 1816 , pequeños grupos de campesinos y artesanos pobres lucharon, bajo el mando de los curas Hidalgo y Morelos, contra la aduinistración española en Nueva España, pero no contra el rey español. Incluso corrió el rumor - y todos los sublevados estuvieron convencidos - de que Feruando VII les apoyaba personalmente y que iba detrás de ellos en una carroza blindada. Parccian cxistir muy pocos motivos para confiar en que se podría 
movilizar sin problemas a la población india en la lucha anticolonial, ya fuese en los Andes o en México.

Una vez que se consiguió la independencia con respecto a España, las élites latinoamericanas se encargaron de organizar sus nuevos 'estados naciones'. En general optaron por el modelo de una república constitucional, formalmente basada en la voluntad libre del pueblo y en la igualdad de todos sus ciudadanos. Aunque esa elección se basó en las doctrinas y 'modelos' disponibles en ese momento. también reflejaba los cambios sociales que habia causado la lucha por la independencia. Esta lucha, aunque no fue una revolución social, había movilizado a una gran parte de la población (rural) y había establecido un contacto más directo entre las clases sociales. Sin embargo, la organización de los nuevos Estados no sc basó en un fuerte sentimiento de unidad nacional; $y$ cuando sí existió cierto sentimiento de unidad nacional, ćste careció de un fundamento etnocultural compartido. La afinidad cultural de la élite criolla con la madre patria siguió siendo fuerte y siguió siendo impensable que los demás grupos étnicos tuviesen poder de decisión efectivo en el proceso político.

Los dirigentes de los jóvenes Estados latinoamericanos creían que podrian transformar a los habitantes del territorio nacional en ciudadanos. Sin embargo, esta aspiración chocaba con la supervivencia de los privilegios sociales que de hecho ellos intentaban conservar a través de la nación criolla. La identificación cultural de la élite con la cultura curopea considerada como superior se basó en ideas posteriores populares y positivistas en las que el racismo 'cientifico' estaba representado de forma prominente. Asi, se llevaron a cabo en México y Bolivia, entre otros paises, cefalometrías y otras investigaciones 'raciales' (Leys Stepan, 1992; Demelas, 1981). En este caso influyeron mucho las ideas socio-darwinistas. A pesar de las nociones formales de igualdad y democracia, se mantuvo, al igual que en Europa, un complejo sistema de discriminación étnica.

Sin cmbargo, la élite - blanca - dominante se convenció, aunque no del todo. de que el Estado nacional se debía consolidar a través de la incorporación de los diversos grupos étnicos. Sin embargo, no quedo claro cómo conseguirlo, Así, en un principio las élites colombianas abrigaron la esperanza de poder incorporar a la población indigena y de color dentro de la 'civilización nacional' por medio de la legislación. El objetivo del progreso económico supuso un enorme impulso: se debía transformar la propiedad de tierra comunitaria india en propiedad privada con el fin de fomentar el desarrollo agrario, Por lo demás, en términos generales la moral de trabajo y de consumo de los colombianos debía seguir el cjemplo curopeo. Durante la guerra de la independencia los colombianos blancos ilustrados atribuyeron el 'atraso indio' a las restricciones 
que el sistema colonial de clases y tributos les habia impuesto. Sin embargo, la legislación liberal con respecto a la propiedad india de la tierra de después de 1821 condujo a que la tierra, en su mayor parte, cayese en manos de los que no eran indios.

Aunque la incorporación cultural y política de los indios fue un objetivo importante de la legislación, esta situación fue distinta con respecto a los afrocolombianos. El micdo a los sucesos en Haiti - en parte basados en prejuicios sobre el supuesto carácter temperamental de los negros y mulatos - dominó el pensamiento de la élite. Además, influyó mucho, al igual que en toda Latinoamérica, la cuestión de la abolición o el mantenimiento de la esclavitud. Los nuevos dirigentes criollos tuvieron muchas más reservas con respecto a esta cuestión que con respecto al reconociniento de la igualdad civil de los indios y de los negros libres. Casi en ningún sitio se abolió la esclavitud justo después de la independencia. En la mayoria de las repúblicas hispanoamericanas la abolición se produjo entre 1840 y 1870 . En Brasil la independencia no acabó en absoluto con la hegemonía de la élite que disponía de esclavos. A pesar de una prohibición legal impuesta por Inglaterra en 1831, lasta 1851 se importaron más 650,000 esclavos de Africa. El problema de la incompatibilidad de la esclavitud con el principio de los derechos civiles fue menos acuciante debido a la supervivencia de rasgos absolutistas en el sistema politico, y más en general a la cultura política autoritaria del país.

El liberalismo latinoamericano generalmente predominante y orientado al desarrollo económico adoptó una postura nuy ambigua con respecto a la cuestión de la esclavitud. Los partidarios de la esclavitud sostenían que el derecho inalicnable a la propiedad privada también se debia aplicar a los que tenían esclavos. Naturalmente este argumento sólo se podía mantener mientras se considerara más importante el derecho a la propiedad qque la libertad personal del individuo. Para defender esto fuc necesaria una 'deshumanización" idcológica del africano; el antiguo argumento de que los negros apenas eran gente. Sin embargo, éste no fue el único argumento aducido por los partidarios de la esclavitud. Otros argumentos, a veces contradictorios, giraban en torno al efecto cdificante de la esclavitud en la población negra mediante el 'contacto cultural' o un trato paternalista, o en torno a la 'eficacia superior' del trabajo de esclavos. Los defensores de la esclavitud en Hispanoamérica y Brasil se basaban incluso más en la necesidad econónica de la esclavitud o en la imposibilidad politica de la abolición que en argumentos étnicos o raciales.

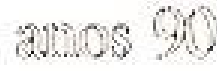




\section{FORMACIÓN DE ESTADOS Y RESISTENCIA 'ÉTNICA'}

A pesar del carácter represivo y a menudo violento de la formación de Estados en Latinoamérica y en partes del Caribe, hubo relativamente poca resistencia a los resultados del proceso. Eso no quiere decir que no se produjesen sublevaciones de indios, esclavos, negros o mulatos. En el capitulo anterior ya tratamos en breve sobre la llamada guerra de castas en México, en la que los mayas y los yaquis se opusieron a la centralización del poder político. En el Caribe los esclavos o los mulatos libres y sus descendientes a menudo se rebelaron contra el sistema de plantación colonial. Sin embargo, a excepción de Haití, en ningún sitio tuvo lugar una guerra étnica por la independencia que tuviera éxito.

La lucha politica y militar en la Latinoamérica del siglo XIX cstuvo dominada por luchas por el poder estatal entre las élites políticas o regionales rivales. A veces también los movimientos étnicos influycron en estas confrontaciones militares. Así los enfrentamientos militares pudieron contribuir a introducir cambios sociales. A veces la población negra o mulata se sirvió de las sublevaciones regionales, que estallaron en Brasil entre 1830 y 1845 , para resistirse a las autoridades, aunque en primer lugar se trató de conflictos entre las élites regionales y la monarquia centralista. De la misma forma, el movimicnto indio de Zarate Willka en la Bolivia del siglo XIX prosperó tanto debido. en parte, a que se unieron a los Liberales en la lucha por el poder politico.

El cjemplo más representativo de un movimiento étnico, que sacó provecho de una coyuntura política, es el caso de los Montoneros, quienes durante la Guerra del Pacífico (1879-1882) lucharon en el bando del ejército peruano contra el ejército invasor chileno en el sur de Perú. Mientras que la resistencia peruata se sofocó enseguida. las tropas 'indias' independientes siguieron luchando sin descanso. En un primer momento recibieron las alabanzas de la élite peruana por su valentía. pero cuando, basăndose en su origen indio, cmpezaron a fundar pequeñas repúblicas campesinas independientes, a exigir la autononia para sus pueblos y también a ocupar tierras de las haciendas, pronto esta aprobación fue sustituida por una fuerte represión. A pesal de cllo, hasta principios del siglo XX el Gobierno no consiguió acabar con la autonomía de estos pequefios Estados campesinos indios.

Las autoridades de los nuevos Estados sinticron un gran temor hacia esas manifestaciones de resistencia étnica. No es de extrañar, porque la ideologia

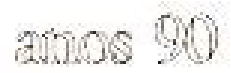


del siglo XIX sobre la formación de Estados quería que la población dentro de los límites nacionales fuera igual $\mathrm{c}$ indivisible. Este fue también el telón de fondo de los intentos de Bolivar por conseguir transformar a todos los latinoamericanos en ciudadanos. Una vez que a cada miembro de un Estado se le podia calificar con el mismo término. se había llevado a cabo el primer paso hacia la igualdad. Los movimientos que ponian en tela de juicio este principio, minaban la autoridad del Gobierno. Incluso dejando a un lado el miedo al separatismo étnico armado, esta ideología implicaba la represión étnica de cualquier movimiento étnico, por insignificante que fuera.

Por irónico que parczca. a veces a los propios miembros de estos movimientos se les escapaba el supuesto carácter 'étnico'. Canudos, una pequeña ciudad en el interior (sertão) de Bahia, es un buen ejemplo. A partir de 1893, cuatro afios después de la proclamación de la República, surgió Canudos como asentamiento y fue crecicndo hasta convertirse en un lugar de peregrinación. Vivian aproximadamente veinte mil personas, por lo general procedentes del campo de las áridas provincias del nordeste de Brasil. Esta pequeña ciudad fue fundada por el devoto cura laico calólico Antonio Vicente Mendes Maciel conselheiro. Sus seguidores constituian un grupo helerogéneo de mestizos, mulatos y negros, a menudo denominados simplemente caboclos. El mundo exterior tenia una opinión extremadamente parcial y negativa de Canudos. Finalmente las autoridades decidieron destruir el asentamiento. Sólo lo consiguicron en el cuarto intento, cuando cinco mil soldados conquistaron la 'ciudad santa' haciendo un gran alarde de poder. Estos creyentes habian huido de la sequía y de unas condiciones de vida desfavorables del sertăo y vieron en el conselheiro (cl Consejero) a un guia que les ofrecia cobijo y seguridad. Nada en las fuentes disponibles apunta que hubiese un peligroso ejército rebelde y 'étnico' dirigido por un maniaco fanático y formado por negros y mulatos.

Esta formación del mito es instructiva. Canudos no sólo inspiró desconfianza y enemistad entre la élite del Estado de Bahia. que veía al movimiento como una amenaza a su posición de poder tradicional, sino que además 'Canudos' se convirtió también en un asunto nacional, La joven y poco estable República brasileña vio en este movimicnto una amenaza direcla a la frágil unidad nacional y al orden. Esto estuvo esirechamente relacionado con el carácter étnico que se le atribuyó al movimiento. Euclides da Cunha (1983, I:6) caracterizó a los habitantes de Canudos en su epopeya Os Sertões como una banda de agitadores negros: «La civilización avanzará a través del irreconciliable motor de la historia en el sertão. Las razas fuertes aplastarán a las razas débiles.» E1 Estado representó naturalmente a las razas 'fuertes'. Por otra parte da Cunha lamentó la violencia exirema con que se había destruido 
el asentamiento. Esto también ilustra que dentro de la élite se pensaba de distintas maneras sobre la manera en que se debia combatir el 'desafio étnico'.

Otro ejemplo de esta 'etnicidad involuntaria' lo tenemos en Cuba, donde durante el siglo XIX se había desarrollado una situación social explosiva. Tras la eliminación de Haiti, esta isla creció hasta convertirse en el mayor productor de azúcar del mundo. Hasta 1865 se trajeron miles y miles de esclavos, seguidos de unos 125.000 trabajadores chinos con contrato y - entre 1880 y 1920 - a más de 600.000 inmigrantes españoles. Cuando en 1902 Cuba consiguió la independencia, en el pais predominaban los contrastes ent re las clases y grupos étnicos. Los afro-cubanos, que durante la lucha por la independencia habian desempeñado un papel destacado, pronto se vicron privados de derechos y posibilidades politicas de participar de forma equivalente en la sociedad civil. Esto se opuso diametralmente a las cxpectativas que se habian despertado en este grupo de población con respecto a la lucha anticolonial. Además, los factores sociocconómicos pusieron en aprietos a partes de la población afro-cubana. Pérez (1986) muestra cómo en la provincia Oriente los campesinos afro-cubanos - antiguos esclavos - que en décadas anteriores se habían refugiado alli, ahora se veían presionados por la producción de azúcar procedente del oeste de pais $y$ por la afluencia de inmigrantes nuevos.

Como reacción a sus problemas, los representantes del grupo demográfico afro-cubano fundaron en 1907 un partido, cuyo punto principal del programa era la supresión de la discriminación social y política de los negros y mulatos. Sin embargo, este movimiento fue bastante elitista; los campesinos y la gente sin tierras procedentes de Oriente se podian identificar difícilmente con este partido. Cuando en 1910 se probibió este partido argumentando que no se toleraban organizaciones raciales en la nueva Cuba, los afro-cubanos más pobres tomaron las riendas y pasaron a formas más radicales de resistencia. Sin embargo, la principal exigencia de estos rebeldes fue también la igualdad étnica. La sublevación en Oriente creció hasta convertirse en una combinación de resistencia campesina, furia popular y bandidajc, Las tensiones étnicas seguian influyendo superficialmente en la sociedad cubana. Aunque en realidad los rebeldes sólo luchaban por la ciudadania de pleno derecho, la élite gobernante (blanca) no lo veía así. El miedo a una sublevación general de la población afro-cubana constituye una explicación importante al hecho de que la rebelión fue reprimida implacablemente. Resulta muy significativo que este conflicto pasó a la historia como la guerra de razas. Con esta denominación 'hegemónica' se sugería que los afro-cubanos querian provocar una guerra civil racial - mientras que sólo lucharon por conseguir los mismos derechos civiles dentro de la república cubana. 


\section{CIUDADANÍA, INCORPORACIÓN Y EXCLUSIÓN}

En general, la adjudicación de derechos civiles formales a los grupos de población indígenas y afro-americanos tuvo en la práctica un efecto limilado hasta bien entrado el siglo XIX. Por lo general laı arbitrariedad juridica y politica pesaba más que los derechos democráticos establecidos constitucionalmente. Dominaban las relaciones personales. En la vida diaria la discriminación en base a la clase, la posición social, la formación la religión y la etnicidad era lo normal.

Tras 1870 el proceso de formación de Estados en Latinoamérica cambió de carácter. Las inslituciones personales empezaron ser sustituidas por estructuras estatales más autónomas. Aunque había discrepancias sobre las fronteras, ya no se cuestionaba la legitimidad de las repúblicas independientes en sí. A partir de entonces las élites nacionales pudieron centrarse en la formación de naciones y en la incorporación de la población dentro de su proyecto politico. La nueva fase estuvo vinculada también al crecimiento económico y a la diversificación social que se produjo en Latinoamérica. Esto actualizó de nucvo el problema de la incorporación social y política de la población. Clases y grupos antiguos y nuevos fuvieron que encontrar su sitio en un orden existente que no estaba bien equipado para este fin. En este nuevo contexto, la gente empezó a pensar en lérminos de una 'comunidad de intereses civiles'. Además de la adjudicación formal de la ciudadanía, en ese momento también se incluyó en el orden del día político la incorporación efectiva de la mayoria de la población. Por primera ver la 'nación' y el 'pueblo' se convirtieron en una categoría importante en el proceso de formación de naciones.

En muchos análisis de Latinoamérica, se subraya el carácter inlıerente débil de la sociedad civil del siglo XX. El Estado ocupa una posición dominante en la sociedad, específicamente con respecto al tratamiento de los conflictos. sociales. A pesar de los principios constitucionales formulados generalmente surgicron regímenes muy centralistas. La necesidad de 'incorporación de las masas en una comunidad de intereses nacional reconocida (Estado de compromiso) dio un fuerte impulso al surgimiento de formas de gobierno populistas. Touraine (1989) señaló que estos regímenes populistas a menudo se alzan como defensores de la cultura popular nacional. El curocentrismo no fue la doctrina más apropiada para el nacionalismo de las masas o para la movilización del pueblo. Por otra parte, dentro del populismo siguió siendo de vital importancia el ideal de la unidad etnocultural del pueblo.

Hasta hoy en dia es patente la tensión entre la construcción necesaria de una nación y la impotencia de poder aceptar la heterogeneidad étnica. Los regimenes dictatoriales. que desde los años sesenta dominaron la política 
latinoamericana como consecuencia del fracaso del modelo populista, intentaron volver a vincular en mayor grado la 'esencia' de la nación al Estado. Con el debilitamiento de las dictaduras a partir de 1979 volvió a saltar a la luz el problema de la construcción de una comunidad de intereses civiles. La vuelta a un sistema parlamentario no sólo volvió a abrir el debate sobre los derechos civiles y politicos (es decir los dercchos humanos) en Latinoamérica, sino también sobre la dimensión social y cultural de la ciudadania.

En cstos casos la etnicidad se presenta de distintas maneras. En algunos paises del sur, sobre todo en Uruguay, Argentina y Chile, se llevaron a cabo relativamente pronto reformas sociales radicales para ratificar la participación de distintas clases en la nación, El florecimiento de la economia de exportación hizo posible que se forjaran compromisos entre las élites establecidas, las 'nuevas' clases medias y el proletariado que empezaba a surgir. Se amplió la participación politica y se desarrollaron servicios sociales. Aunque no está del todo claro, sigue resultando intrigante si este 'ćxito' estuvo relacionado con el hecho de que se trataba de paises relativamente homogéneos desde el punto de vista étnico. La proporción numérica de la población afro-americana en estos países era muy baja y en gran parte ya se había suprimido o climinado a la población india.

Resulta curioso el debate étnico que surgió en estos paises sobre la inmigración masiva procedente del sur de Europa, sobre todo italianos y espaĩoles. La élite argentina - que probablemente consideraba que habia superado su propio origen - empezó a preocuparse por la contaminación del alma popular argentina debido a la llegada de inmigrantes blancos de 'segundo rango', entre los cuales, por otra parte, a menudo también se incluia a los inmigrantes judíos. La comunidad lingüistica política y académica en Buenos Aires elaboró todo tipo de 'nucvos' razonamientos étnicos, encaminados a legitimar esta discriminación. Basándose en las ideas corrientes sobre la base biogenética de la conducta de los rebeldes criminales y politioos ('anarquistas'), se abogó por una legislación sobre inmigración restrictiva para mantener fuera del país a 'razas' no deseadas.

Por ofra parte, los que criticaban tales posturas se servían también de razontamientos 'étnicos'. Un argumento para la incorporación social de estos inmigrantes fue que un mejoramiento de sus condiciones de vida y de los servicios sociales desembocaria en un 'mejoramiento racial'. Zimmerman (1992) señala que la 'invención' de la diferenciación étnica entre blancos en un país como Argentina demuestra la fuerza de las ideas sobre la superioridad e inferioridad étnica en las primeras décadas de este siglo. Además, el hecho de que los inmigrantes italianos, a quienes en Buenos Aires se les veía con desconfianzay desdén, fueran acogidos con entusiasmo en el país vecino Brasil, 
no sólo para asumir cl trabajo de los esclavos, sino también para fortalecer el ardiente deseo de blanquear a la población brasileĩa, demuestra que estas teorias a su vez estaban vinculadas a un contexto especifico.

Por otra parte, la etnicidad e incluso la raza se consideraban como categorías cambiables en estos debates de finales del siglo. Se suponía que en la lucha por la existencia social la mezcla étnica, la disciplina, las normas sociales y sobre todo la educación sacarian a la luz las mejores cualidades étnicas.

\section{ETNICIDAD Y CLASE: AFRO-BRASIL}

Tras la abolición - tardia - en Brasil (1888). los afro-brasileños empezaron a participar como ciudadanos libres en una sociedad que se desarrolló rípidamente y que se caracterizó por la enorme desigualdad material y social. Es indudable que esta desigualdad coincidia con las fronteras étnicas. La situación real se contraponía a la idea de la democracia racial, que en el transcurso del siglo XX pasó a ocupar un lugar tan docisivo en el discurso nacionalista de la élite brasileña. Por eso los investigadores que en los años cincuenta y sesenta de este siglo se dedicaron a estudiar la posición social de la población afro-americana en Brasil, se basaron en esa realidad para criticar la idea de la 'democracia racial'. Según ellos, la idea de igualdad entre las 'razas' no tenía ninguta base teniendo en cuenta la marginación sistemática de los negros y mulatos brasileños.

El sociólogo Florestan Fernandes, junto con otros investigadores ahora renombrados de la Universidad de São Paulo (entre quienes figuran Fernando Henrique Cardoso y Oclávio Ianni), elaboró este planteamiento de raza-clase en una obra clásica que se ha hecho casi paradigmática (Fernandes 1969). Sirviéndose de las investigaciones empíricas sobre la ciudad de São Paulo, analizó la situación de la población afro-brasilenia. Relacionó su posición subordinada 110 sólo con la herencia de la esclavitud, sino también con la 'modernidad' incompleta de la sociedad brasilena entre 1880 y mediados del siglo XX. Tras la abolición de la csclavitud, los afro-brasileños estuvieron mal preparados cultural y psicológicamente para competir con los recién llegados de Europa (sobre todo italianos) en el ucdio urbano. Las élites intentaron mantener la subordinación de los negros brasileños, porque les beneficiaba. Además los trabajadores blancos también intertaron conservar su posición superior con respecto a los negros - un fenómeno que en ese periodo también se produjo en países como Estados Unidos. Cuba y Sudáfrica. Por eso, la mayoria

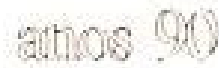


de los afro-brasileños sólo tuvieron acceso al sector informal de la cconomía urbana que creció de forma explosiva.

Después de 1945 la rájida evolución de la sociedad brasileña urbanoindustrial acarreó, según Fernandes, la individualización de la población afrobrasileña en São Paulo. Se pasó a poner el énfasis en la movilidad social individual. Efectivamente aumentaron las posibilidades de ascenso. Sin embargo, sólo algunos afro-brasileños consiguieron escapar a la pobreza y a las categorias del proletariado informal para entrar a formar parte de las clases sociales 'formales' del proletariado o de la clase media. El cstudio de Fernandes demuestra cómo los prejuicios étnicos contribuyeron a impedir una participación efectiva de los negros y de los mulatos.

Desde cntonces se han formulado muchas críticas a la visión de Fernandes. Los críticos sostenian que la relación entre etnicidad y desigualdad social es mucho mís compleja de lo que se puede suponer basándose en las influencias supuestas del 'retraso cultural', en un pasado de esclavitud y en la desigualdad de clases existente. Andrews (1988) demuestra, por ejemplo, que no se pueden encontrar diferencias convincentes en la experiencia laboral, ni cn las aptitudes, ni tampoco en la autoconciencia cultural que los ex-esclavos e immigrantes en São Paulo tenian entre 1890 y 1920 . Este autor atribuye la exclusión de los negros del mercado laboral regular, sobre todo, a la política de las autoridades del Estado de São Paulo donuinada por la clase de los propietarios de plantaciones, que con su política de inmigración y con su represión de las organizaciones obreras multićt nicas, intervino deliberadamente en el mercado laboral de ese Estado. Prejuicios hacia los negros 'vagos' e 'incompetentes' hicieron que los propictarios de plantaciones y los fabricantes prefirieran a los inmigrantes. Esto se vio reforzado por la disposición original de los inmigrantes procedentes del sur de Europa a aceptar salarios más bajos, trabajo familiar y unas condiciones de vida y de trabajo más desfavorables. Los ex-esclavos se negaron a aceptar esas condiciones porque temían caer de nuevo en condiciones similares a la esclavitud. Sólo cuando en el transcurso de los años veinte la complacencia de los immigrantes se convirtió en resistencia a las malas condiciones laborales se puso fin a la preferencia por los europeos y se cortó la inmigración subvencionada.

Hasenbalg (1979) intentó analizar la relación entre la diferenciación étnica y la estratificación social en Brasil desde 1945 sin reducir de antemano la desigualdad étnica a la desigualdad de clases. Sus datos investigativos recopilados en la primera mitad de los atios setenta, en pleno apogeo del 'milagro cconómico' brasileño, demostraron una relación sistemática entre el 'color de la piel', es decir el estatus de blanco, negro o mulato, y la posición social. Demostró que los afro-brasileños, por lo general, ocupaban posiciones bajas y 
también que su movilidad social ascendente era mucho menor de lo que Fernandes pensó que se podia esperar quince aĩos antes. Las posibilidades de una movilidad social ascendente eran para los que 'no eran blancos' mucho menores que para los blancos. Hasenbalg atribuye esto a las prácticas discriminatorias sutiles y al racismo simplemente. La exclusión basada en los prejuicios étnicos tiene en esta óptica una 'autonomía' propia y este fenómeno no desaparecerá automáticamente como consecuencia de una modernización posterior de la sociedad de clases.

Sin embargo, nos parce demasiado rotundo atribuir los prejuicios y la discriminación con respecto a los negros exclusivamente a un plan premeditado de las élites de tendencia autoritaria, tal y como hace Hasenbalg. Asi se sigue prestando poca atención tanto al carácter dinámico de la distinción étnica tal y como lo viven ambas partes, como al carácter complejo de las estrategias énicas. Además un enfoque en la desigualdad sociocconómica no tiene en cuenta las dimensiones politicas y culturales del problema.

Las relaciones políticas cambiantes desde finales de los años setenta impulsaron cada vez a más afro-brasileños a criticar la dimensión étnica de la desigualdad social y el mito de la democracia racial. Sin embargo, los portavoces eran sobre todo afro-brasiletios con una buena formación, que unieron sus objeciones étnicas a una oposición radical de izquierdas con una base de apoyo uás amplia en contra del régimen militar. Tras la formación de un Gobierno civil en 1985 estas protestas tuvieron más eco en los partidos políticos, que buscaban una base de apoyo que en los habitantes de las favelas.

Sin embargo, en este contexto sí se ha conseguido algún adelanto. El Estado brasilcĭo reconoció por primera vez que la discriminación de negros y mulatos era un problema contra el cual se debia elaborar una política oficial. Sólo en la constitución de 1988 sc penalizó la discriminación en base a la raza o cl color de la piel. Desde entonces, con regularidad los medios de comunicación también han prestado atención a la discriminación real y a los prejuicios contra los negros en el 'paraíso racial' brasileño. Sin embargo, la experiencia en paíscs como Estados Unidos sugiere que hay un largo camino que recorrer entre el reconocimiento oficial y el mejoramiento efectivo de la posición social y econónica de la población afro-americana. La fuerte correlación entre ctuicidad y clase social todavía persistirá durante mucho tiempo en Brasil. 


\section{REVOLUCIÓN Y MOVILIZACIÓN ÉTNICA}

En cl siglo XX la movilización y la incorporación énica también influyeron en las llamadas revoluciones 'nacionales'. En este contexto, los ejemplos de las revoluciones en México, Cuba y Nicaragua son instructivos. En cstos casos. los revolucionarios apostaron por la etnia como apoyo a la lucha socioeconómica de las masas populares. Esta conexión acarreó, por lo general, problemas porque la dinámica de la movilización étnica era dificil de controlar. Por otra parte, a menudo tras la supuesta movilización 'étnica' se escondia una movilización patente en base a la clase. Así por lo general se parte de la idea de que la Rcvolucjón Mexicana (1910) se apoyó, en gran parte, en los campesinos 'indios'. que aprovecharon la ocasión para rebelarse contra la explotación bajo la dictadura de Porlirio Díaz (1876-1910). Sin embargo. fue mucho más la posición social de los campesinos que una movilización de base étnica lo que determinó la participación de la población rural en la lucha revolucionaria.

En el periodo posterior en el que se consolidó el nuevo orden, se elaboró por parte del Estado una forma oficial de indigenismo y se construyó la noción de la 'raza cósunica' de los mestizos, con lo cual se sirvió un objetivo explícitamente politico, que sólo se puede entender en el marco de la continuidad entre la revolución y la organización política prerrevolucionaria del campo mexicano. De hecho hasta principios de este siglo el régimen de Porfirio Díaz. mantuvo la autonomía de las clases, que se remontaba la época colonial. Las comunidades nurales fueron controladas por los 'notables indios', los caciques, que formaban una de las bases de apoyo importantes del régimen. Después de 1900, inesperadamente, el Estado acabó con esta situación, como parte de una estrategia para 'tnodernizar' el Gobicrno. Por eso la participación de los 'jefes campesinos' en la lucha revolucionaria se puede entender como un intento de Jos caciques de recuperar su situación. Su 'clase' era imprescindible para la movilización de la población campesina en la lucha armada. Finalmente, el Estudo revolucionario 'instilucionalizado' incorporó las distintas milicias dentro de un sistema político con fuertes rasgos corporativistas. Se supone que a partir de entonces el clemento 'indio' se asimiló a la cultura mestiza 'cósmica' nacional.

También en la Cuba revolucionaria las autoridades se vieron obligadas a encontrar una respuesta a la relación entre la idcología y la existencia de fronteras élnicas muy enraizadas. En este caso, el objetivo declarado de las intervenciones estatales no fue la adaptación a una cultura considerada superior, sino la igualdad cultural y énica. La revolución cubana (1959) puso como norma la igualdad cotidiana e intentó fomentar la participación de los negros 
y de los mulatos en la sociedad. Esta política supuso una ruptura formal con la situación anterior a 1959, cuando se consideraba a los afro-cubanos como ciudadanos de segunda catcgoría. Estos sentimientos tenían sus raices en la esclavitud, pero fueron reforzados, al igual que, por ejemplo, en Brasil y Estados Unidos, por la inmigración masiva curopea en el periodo posterior a la abolición de la esclavitud. Además se reforzó la jerarquización étnica debido por una parte a la inmigración de obreros negros del sector azucarero procedentes de Haití y el Caribe británico y por otra a la influencia politica creciente y a la presencia militar y económica de Estados Unidos.

Según parece la revolución, a pesar de toda la retórica y las medidas efectivas, no pudo acabar con los patrones de discriminación racial y étnica formados a lo largo de varios siglos. Desde 1959, la ideología ha sido daltoniana. La discriminación racial se abolió totalmente de manera formal y naturatmente aumentó mucho. por ejemplo, la proporción de afro-cubanos en las escuelas y en las universidades y en los cuadros intermedios. Sin embargo, los altos cargos están todavia casi exclusivamente ocupados por blancos y también dentro de esta élite abundan los prejuicios raciales. Además, por lo menos hasta hace pocos años, ni tan siquiera se cuestionaba la aceptación igualitaria de los bienes culturales afro-cubanos en la cultura revolucionaria. Sin embargo, si se aceptó la música afro-cubana bajo el lema 'todo dentro, nada contra la revolución' e incluso se convirtió en un articulo de exportación revolucionario y cultural atractivo. Por el contrario, hasta hace poco la religión afro-cubana santeria fue considerada como subversiva y fue reprimida. La revaloración reciente de esta religión parcce explicarse más por la necesidad del régimen de conseguir más apoyo entre la población cubana que por un cambio de las propias ideas. Por tanto el caso cubano en primer lugar parece recalcar que es muy dificil cambiar los prejuicios que se han ido desarrollando históricamente y que ese proceso dura mucho ticmpo.

Sin embargo, desde una perspectiva casi maquiavélica, se podria decir que en todo caso la politica y la retórica de la rev jlución fidelista han conseguido que la población negra se haya convertido en uno de los pilares más importantes de la revolución. Según las estimaciones, la proporción afro-cubana en la población total ha aumentado del $40 \%$ al $60 \%$ aproximadamente desde 1959 hasta ahora, lo cual se debe en parte al hecho de que los cubanos que desde entonces han abandonado la isla sean predominantemente blancos. De ahí, la gran importancia de mantener a la población negra en favor de la revolución. En este marco encajaba la catalogación de Cuba como afro-latina y caribeña y las intervenciones en Africa, la retórica de una continuidad (cien años de lucha) de la lucha contra Espania, el colonialismo, Estados Unidos, el imperialismo y el racismo. Curiosamente aunque la población afro-cubana es la que más ha 
progresado relativamente desde 1959 , también al mismo tiempo es la que ahora más está sufriendo bajo la crisis del régimen y la que además teme con razón un posible 'regreso' de los cubanos predominantemente blancos afincados en Florida.

Nicaragua ofrece un último ejemplo de un intento revolucionario de apostar por la vía énica. Durante el Gobiemo sandinista, por lo general los indios miskitos se opusieron radicalmente al Estado. Esta postura se puede explicar en parte por la historia del nacionalismo de los miskitos. La población de la costa de los Mosquitos se diferenciaba social y culturalmente de los habitantes españoles y mestizos del altiplano y de la costa del Océano Pacílico. Además, ya desde principios del siglo XVII constituyó un peón en la lucha entre España y otras potencias, sobre todo Inglaterra y posteriormente Estados Unidos. En 1894 con una expedición militar el presidente nicaragüense José Santos Zelaya puso fin a la relativa autonomía de la que los miskitos habian gozado hasta entonces. A continuación, el Estado intentó, sin mucho éxito, imponer a la población el español y el catolicismo. El establecimiento de plantaciones norteamericanas de bananas dio trabajo a muchos miskitos y refor ó las diferencias sociales y culturales entre los costenios y el resto del país. A partir de los años setenta se movilizaron varias organizaciones étnicas en esa zona, entre las cuales figuraba una que aspiraba al derecho de autodeterminación para los miskitos.

A partir de 1979 esta aspiración se opuso al proyecto revolucionario de los sandinistas. El Gobierno revolucionario creía que también los habitantes de la costa atlíntica apoyarían las reformas, teniendo en cuenta que éstos formaban parte de las clases 'explotadas' de pequeños terratenientes y proletarios rurales. Sin emabargo, los revolucionarios no tuvieron nuy en cuenta el 'nacionalismo étnico' de los miskitos. Además, los miskitos y los demás grupos étnicos de la costa oriental consideraron cl planteamiento encaminado a la 'participación de clases' como una violación de su carácter étnico. Los sandinistas intentaron incorporar a los costeños en 'organizaciones de masas' corporativas, pero permiticron que se crease una nueva organización étnica para la costa oriental. que en la práctica fue dominada por los miskitos. Sus dirigentes se resistieron a la manera en que el Gobierno sandinista quería integrar a los costeños en la revolución. Sus exigencias evolucionaron desde el reconocimicnto de su propio idioma y cultura hasta el control de la tierra y finalmente la independencia. Pronto el miedo de los sandinistas al separatismo predominó sobre la disposición a reconocer los 'dercchos' de los costeños. Poco después, entre 1981 y 1984 , el conflicto resultante entre los 'españoles' procedentes de Managua y los costeños entró en el torbellino de la rivalidad geopolítica ent re Occidente y Oriente, La infiltración de los contras en el hábitat 
'histórico' de los miskitos situado tanto en Nicaragua como en Honduras hizo que el conflicto se acrecentase. El Estado sandinista reaccionó no sólo con la acción militar, sino también con el desplazamiento obligatorio de los pucblos miskitos.

Tras 1984 mejoró la relación entre el Gobierno nicaragüense y los miskitos. La reanudación en 1985 de las negociaciones de paz con los miskitos sublevados, en las que los sandinistas ya no les consideraban exclusivamente como contras, sugiere una disposición por parte del Estado a adoptar una postura más discreta y constructiva. A partir de 1986 las negociaciones entre Managua y los representantes de los distintos grupos étnicos fueron encaminadas al reconocimictito de una atutonomía amplia de estos últimos. Los sandinistas querian ver implantado sobre todo el principio de la 'indivisibilidad' de Nicaragua, con ol fin de hacer sitio dentro de este principio a los derechos sociales, políticos y culturales de los grupos étnicos. A finales de los años ochenta, se consideró este proceso como un experimento importante para explorar las posibilidades y las fronteras de la autonomia étnica dentro de los Estados nacionales en Latinoamérica. En 1988 los dirigentes miskitos más militantes dejaron de resistirse a la estrategia de las negociaciones. Tras la derrota electoral de los sandinistas en 1990, el nuevo Gobierno formado mantuvo los acuerdos existentes con las regiones autonomas situadas a lo largo de la costa caribeña.

\section{MOVIMIENTOS INDÍGENAS Y EL ESTADO LATINOAMERICANO}

El problema nicaragüense no fue un caso aislado. Varios Estados latinoamericanos se vieron enfrentados a los nuevos intentos de sus 'poblaciones procolombinas' de superar las diferencias locales y de organizarse como 'indios'. Como ya indicamos anteriormente, esta estrategia ćtnica fue posible, en parte, gracias a la difusión de la ideología indigenista entre los blancos y mestizos. Sin eubargo, esto tuvo sus consecuencias porque los Estados nacionales después se vicron obligados en casos concretos a determinar su postura frente a los indios y a sus privilegios tradicionales.

Tras la abolición de las clases coloniales, se cambió la autonomía india por la ciudadania, con lo cual uı grupo muy grande de gente perdió los derechos de clase y se liberó de las obligaciones especiales a las que habia estado sometido. En principio se suprimieron los deberes laborales especificos y el tributo. Sin embargo, la realidad fue menos halagüeña. Los nuevos Estados tenían una 
necesidad apremiante de dinero y asi, por ejemplo, en la mayoría de los países andinos después de algunos años se volvió a introducir el tributo para los habitantes de los pueblos anteriormente autónomos. En las primeras décadas después de la independencia, este impuesto supuso a veces el $40 \%$ de los ingresos del Estado. En este contexto fue inevitable una nueva definición del concepto indio.

En el transcurso del siglo XIX y XX, la postura de los dirigentes de los estados naciones experimentó grandes cambios con respecto a los 'privilegios indios': a partir de cntonces a los 'descendientes de los habitantes originales" también se les tuvo que hacer un sitio en el Estado moderno. Este cambio se pucde atribuir al surgimicnto de las ideologias 'indigenistas' en combinación con las nuevas ideas sobre la relación entre ciudadano e incorporación popular. El hecho de que estas ideas sobre todo encontraran partidarios entre la población urbana, no quita que lograran que efectivamente muchos dirigentes del Estado prestaran atención a las exigencias de los movimientos indios. Ya no se reaccionó exclusivamente con incomprensión y violencia, sino que a partir de entonces también se tomó en serio la incorporación de los ciudadanos indios.

Quizás no esté de más indicar que este planteamiento moderno no se llevó a cabo ni mucho menos siempre ni en todas partes. No hay más que pensar en la política de la 'tierra abrasada' del Estado guatemalteco o las matanzas de indios en la zona amazónica. También las autoridades mexicanas, con frecuencia, reaccionaron con violencia antes de reflexionar seriamente sobre las exigencias de la oposición. De nuevo se pone de manifiesto la perseverancia de la diferenciación étnica tradicional. La ambivalencia frente a la población india, en la que una retórica moderna de incorporación choca frecuentemente con una práctica tradicional de exclusión basada en el miedo y en la aversión, sigue siendo característica de la sociedad latinoamericana.

Como ya se ha indicado, durante mucho ticmpo el estudio de la relación entre los estados nacionales en Latinoamérica y los supuestos grupos de población india estuvo marcado por conceptos dualistas o neomarxistas. Los planteamicntos dualistas presentaban a los grupos de población india como representantes de la 'tradición', que vivian en comunidades corporativas cerradas con una identidad cultural propia y 'original' que suponía un obstáculo para la modernización y el desarrollo. Los pensadores liberales de la modernización - al igual que los funcionarios españoles anteriormente consideraban a los indios como nativos vagos. En las teorias de la dependencia se equiparaba a la población india con los campesinos marginados y explotados o con los proletarios rurales. Estas ideas se amoldaron incréblemente bien a las distintas variantes de formación de naciones y modelos nacionales de 
desarrollo que se consolidaron desde finales del siglo pasado. En estas ideas la etnicidad sólo se consideraba como un factor secundario.

Estas visiones encontraron su homólogo en la corriente indigenista, cuyas ideas fueron formuladas hacia finales del siglo pasado por la clase media blanca y mestiza de las ciudades, principalmente en México y Perú. Originalmente el indigenismo tuvo un carácter muy romántico y un interés folklórico en el pasado indio 'intacto'. Debido a ello tenía poco que ver con la realidad diaria de la población india. Sin embargo, el indigenismo acarreó un interés renovado por el elemento indio en la sociedad latinoamericana, que finalmente también adquirió imporlancia en el debate político. Los políticos se dieron cuenta de que sus países eran multiétnicos y de que las autoridades tenían el deber de adoptar medidas para responder a esta situación. En un pais como México el indigenismo se incorporó en la ideología estatal nacionalista, en los paises andinos su influencia fuc limitada, en paises como Guatemala y Brasil apenas tuvo importancia. Presentaremos los distintos resultados mediante varios ejeniplos.

En México, la revolución (1910-1917) incorporó a los grupos indios en la comunidad de intereses nacionales. El indigenismo muy propagado tras la revolución cambió casi totalmente la visión eurocéntrica respecto al indio: cl indio pasó de ser una categoría inferior a transformarse en un elemento vital de la raza mexicana. El pasado heroico azteca sirvió como base para esta visión. Al mismo tiempo el Estado postrrevolucionario aspiró a la incorporación de la población india como parte del mestizaje ensalzado del pueblo mexicano. Sin embargo, la incorporación de los indios a través de un sistema corporativista no pudo acabar con el estatus inferior que se atribuía a los indios en la práctica. Sólo desde los años setenta el Estado mexicano está cediendo algo más, con su 'indegenismo participativo', ante la presión creciente de los movimientos indios para que se reconozca el carácter multicultural de la nación mexicana y para que se atiendan los intereses étnicos específicos de los grupos indios, como por cjemplo, la impartición de la enseĩanza en su propio idioma. Sin embargo, como ya indicamos con anterioridad, el Estado frecuentemente responde en primer lugar a las exigencias de los caciques locales con un programa 'indio' propio.

En Perú, ya desde la época colonial existia una relación antagónica entre la élite española y criolla que dominaba el Gobicrno y a la población india, que predominantenente vivía en el interior. Debido a la obligación de trabajar en la minería colonial, la sociedad nural 'india' había estado menos protegida y los derochos de clase labian tenido menos peso que en Nueva Espania. Por eso, el Estado peruano no tuvo por qué tener tan en cuenta los privilegios indios que databan de la época colonial. Hasta bien entrado el siglo 
$\mathrm{XX}$, las autoridades gobernaron la Sicrra delegando el poder a los dirigentes locales, a quienes a menudo se llamaba gamonales. Por una parte, eso le daba al Gobierno la oportunidad de ejercer algo de influencia en la sociedad rural, pero por otra parte refleja el hecho de que apenas era capaz de disminuir el poder que estos gobcrnantes locales tenian sobre la población india. El gamonalismo, en el que se excluia a la población rural india de la participación social y política, funcionaba como control a distancia.

Sólo en 1968 el régimen militar reformista optó, siguiendo el ejemplo mexicano, por una estrategia de incorporación desde arriba. Sin embargo, los militares no consiguieron ganarse a la población rural india, porque la drástica reforma agraria en ciertos puntos importantes iba en contra de la organización sociocconómica de los propios campesinos. Tras el fracaso de este experimento (1975), el Estado reanudó la antigua estrategia de confrontación y exclusión. Esto desembocó, entre otras cosas, en la radicalización de los intelectuales provinciales y en la creación del movimiento de guerrilla Sendero Luminoso. 'Sendero Luminoso' recurre en parte a una retórica india y se basa en una noción utópica y construida en su mayor parte del 'socialismo indio'. El hecho de que Sendero Luminoso tuviera que movilizar y disciplinar a las comunidades indias con mano dura, demuestra que la mayor parte de la población india siente poco en común con la interpretación radical de Sendero sobre el pasado indio. En cste sentido, se debe considerar esta ideología, al igual que el indigenismo peruano original, sobre todo como un intento de incorporar a la población rural, ya fuese por las buenas o por las malas, en la lucla por el poder nacional.

Sin embargo, desde los ar̃os cincuenta también surgieron en los Andes movimientos marcadamente populares, que se centraban en la causa india. En este contexto Hendricks (1991) y Mallon (1992) hablan, utilizando un término que está de moda. de contrahegemonia ('counterhegemony') para indicar que no se trata únicamente de una estrategia defensiva sino también de una estrategia asertiva de (los dirigentes de) la población rural con el fin de llegar a una redefinición de su posición dentro de los estados nacionales. Bolivia y Ecuador ofrecen ejemplos recientes de esta contrahegemonia. En Bolivia la separación entre los grupos, que cran considerados como blancos, mestizos e indios, estuvo definida tanto geográfica como culturalmente de forma más clara que en Perú. También se produjo antes el intento reformista de incorporación en el Estado boliviano. La revolución de 1952 ya apelaba a los 'indios', pero en primer lugar de forma corporativista, principalnente refiriéndose a su posición como mineros o pequeños campesinos. La población rural se organizó en sindicatos campesinos y mineros, pero también existicron comunidades aymaras dificiles de controlar por el Estado, que además pudicron disponer de una especie de 
'vanguardia' intelectual y politica en La Paz. Esto condujo en los años ochenta a la creación de un movimiento político 'indio', que se basaba en el simbolismo de Tupac Katari, que luchó en la resistencia india de finales del siglo XVIII. Por lo tanto, se optó por una estrategia étnica, independiente de la clase y de las organizaciones sindicales. En las negociaciones con el Estado, los kataristas dicen que defienden los intereses de la 'población india'; en realidad indio en este caso es sinónimo de 'aymaraparlante'.

En los últimos años en Ecuador se está movilizando un movimiento parecido, que ha conseguido crear una plataforma nacional: la Confederación de Nacionalidades Indígenas del Ecuador. La adopción del término indigena, que nunca se habia utilizado anteriormente ni tampoco se reconoce automáticamente, confirma la elección consciente de una estrategia étnica. Antes los grupos rurales se identificaban con su pueblo, región o clase, pero hoy en dia, tras décadas de retórica y débate indigenista, el factor étnico indio ha adquirido importancia para la movilización de los grupos rurales. La organización mencionada formula expliciamente los intereses de los distintos grupos demográficos indios en términos de 'nacionalidad'.

En este caso, curiosamente, parece haber surgido una forma de etnonacionalismo en el que cooperan los 'indios del altiplano', quechuaparlantes, y los 'indios tribales' de la llanura tropical. Los primeros cuentan con una larga tradición de organización comunal local encaminada a1 acceso a la tierra. Estas organizaciones se politizaron tras la reforma agraria en los atios setenta. Entre los 'indios de la llanura', sobre todo influyó la federación de grupos shuarparlantes creada en 1964. Hendricks (1991) atribuye el éxito de la federación de shuars a la conciencia cultural desarrollada o quizás recién nacida de grupos que saben que son diferentes lingüistica y culturalmente con respecto al Estado. Estos supieron imponerse sirviéndose de su fama de gucrreros intransigentes. El Estado ecuatoriano enseguida procedió a reconocer la federación cono una instancia defensora de intereses. No sólo se recurrió a esta federación para los programas encaminados al bienestar social y cultural, sino tambićn para la vigilancia de la zona fronteriza contra las patrullas militares peruanas. De esta manera, el Estado ecuatoriano reconoció implícitamente los derechos 'nacionales' de este movimiento.

Indudablemente, el 'despertar' de la 'conciencia india' en estos paises tiene una relación directa con el desarrollo de la comunidad de intereses nacionales y con las nociones modernas de ciudadanía. Grupos distintos se dan cuenta de que son participantes en este proceso. Los casos de los que acabamos de hablar, en los que se cstá buscando una solución relativamente pacífica a las tensiones potenciales entre las autoridades y los indios, contrastan violenamente con la suerie de la población rural en Guatemala. En este país 
los blancos y ladinos (mestizos) siempre han sentido un gran desprecio por los mayas que les rodeaban. Sin embargo, esta élite dependia del trabajo de los mayas para el cultivo de café y algodón. Las autoridades desempeñaron un papel administrativo y legislativo en el reclutamiento del trabajo obligatorio de los indios. Esto acarreó una relación muy antagónica entre las autoridades y la población india. En la época de la Guerra Fria, el Estado, y sobre todo los militares, temieron mucho el 'peligro subversivo' que partiria de los mayas. Efectivamente, el 'despertar' político de los mayas como respuesta al empcoramiento de las condiciones de vida en el campo hizo que varios dirigentes mayas empezaran a simpatizar con la guerrilla que se estaba llevando a cabo en el interior. Por cso, en Ciudad de Guatemala se consideró a los mayas, y en particular a los quiches, no sólo como adversarios políticos y como enemigos del Estado nacional, sino incluso como un elemento antinacional contra cl cual se legitimó cualquier medida represiva imaginable. En un periodo detcrminado la represión tomó incluso un carácter radical protestante, cuando el Ejército fue dirigido por los Cristianos Recién Nacidos ('new-born (hristians'), que equiparaban a la Iglcsia católica con el 'peligro comunista'. El asesinato de decenas de miles de mayas, de quienes se sospechaba que estaban involucrados en actividades 'subversivas', provocó otras tantas huidas a México para evitar la contrainsurrección brutal del Ejército. Al mismo ticmpo, se produjo un cierto acercamiento entre los dirigentes mayas y los movimientos políticos urbanos centrados en la protección de los derechos humanos y en la democratización. Durante los últimos años los dirigentes de la guerrilla, que dicen hablar en nombre de los mayas y que luchan por una autonomía política de los herederos de la población indigena, incluso han entablado un diálogo con los representantes del Estado y del Ejército. El hecho de que una gran parte de la población india se haya hecho entretanto también protestante, probablemente tenga que ver con esta maniobra.

Finalmente, la historia de la relación entre los indios y el Estado cn Brasil difiere mucho de la de Hispanoamérica. Hasta bien entrado el siglo XIX, el Estado brasileño hizo 'guerras de indios' equiparables a las de Estados Unidos y Argentina. Tras los informes de las expediciones del mariscal Cándido Rondón, a principios de este siglo, empezó a predominar una postura más benévola, enfocada a la integración. Esta postura estaba relacionada con el programa de una corriente 'positivista' dentro de la política brasileña, que aspiraba a la tutela no conflictiva del Estado sobre una nación brasilefia que se consideraba como una colectividad indivisible. De acuerdo con esta política, después de 1900, se elaboró una variante brasileña del indigenismo, orientada a la 'protección paternal' de los indios pacificados. En 1911 se creó el Serviço de Proteção aos Indios (SPI), Este servicio debía proteger los derechos de los 
indios a la utilización de la tierra y la cultura india. Poco después la posición legal de los indios tribales pasó de una tutcla total a una 'minoría de edad temporal', durante la cual el Estado se encargó de la incorporación de los indios en la sociedad brasilefía.

En 1967 las autoridades militares reorganizaron la politica referente a los indios. Disolvieron cl SPI y crearon la Fundaçao Nacional do Indio (FUNAI). Esta fundación es -todavia - una agencia de indios que pertenece al Ministerio del Interior. El trabajo de la FUNAI consistió en ejecutar la politica oficial de delimitación y adjudicación de las rescrvas indigenas. Esta política fue parte de la estrategia de los Gobicrnos militares para organizar de forma racional la explotación de la zona amazónica y el dominio geopolítico del 'vacio'. En la práctica, este objetivo se vio totalmente contrariado por la apertura a gran escala de la cuenca del Amazonas y por la inefectividad burocrática del Estado brasileño. La constifución democrática de 1988 ofrecia formalmente más garantías jurídicas a los indios tribales. Se formuló de forma más rígida el derecho a la tierra y se reconoció como 'original', aunque de todos modos el Estado siguió manteniendo $\mathrm{cl}$ poder de decisión final sobre este derecho. Se suprimió el estatus de menor de edad y finalmente se les dio a los indios la posibilidad de defender sus intereses como personas jurídicas de pleno derecho. Sin embargo, la FUNAI siguió ejerciendo su papel de vigilante.

La movilización de los grupos tribales desde los años setenta ha contribuido a aumentar progresivamente la sensibilidad ante los derechos de los indios entre los partidos políticos y las organizaciones sociales en Brasil. Unidos en uma plataforma nacional, la União das Naçocs Indigenas (UNI) - en cste caso también se utiliza la palabra 'indígena' para movilizar a todos los 'indios' - consiguieron que el apoyo internacional aumentara en los años ochenta. Algunos grupos supieron sacar provecho efectivo de este apoyo recalcando sus derechos a las reservas y reforzando su imagen internacional. También supieron convencer al Banco Mundial de que no financiara proyectos que fueran perjudiciales para el hábitat de los indios. La respuesta por parte del Estado es ambivalente. Aunque en teoría apoya cstos cambios, en la práctica hace poco para que también se lleven a cabo. Además, frecuentemente la élite brasileña se siente herida en su orgullo nacional por la injerencia extranjera.

Cuando intentamos descubrir una línea en estos movimientos indios dispares y en su relación con el Estado latinoamericano moderno, llegamos con cautcla a la siguiente conclusión. En paises con un grupo de población grande que, definiriamos como indios - porque hablan su propio idioma, conservan una cultura regional o incluso local diferente, porque se han mantenido alejados durantc mucho tiempo del estado nacional -, los grupos locales y regionales, influidos por la evolución de las autoridades centrales y 
de las instituciones modernas capitalistas, se han concientizado de su posición y de sus derechos a la participación plena en el Estado nacional. En un principio, el Estado obligó a estos gnupos a participar en el proyecto de unificación nacional renunciando a su propia identidad. Esta coacción condujo hasta hace relativamente poco ticmpo a una fuerte represión, a menudo influida por la Guerra Fría. Sin embargo, cuando quedó claro que se había concluido la lucha geopolítica y cuando una gran parte de la élite se dio cuenta de que quizás la protesta rural no se fundaba en el comunismo, el Estado se abrió más a la supervivencia de unidades 'étnicas' distintas dentro de las fronteras nacionales. En esta protesta los dirigentes locales y regionales se han concientizado cada vez más de su etnicidad 'india' y de la posibilidad de que se escuchen sus exigencias con respecto a la autononía política y jurídica y en cuanto a la ciudadanía de pleno derecho, Por irónico que parezca, la autonomía que estos grupos exigen muestra un parecido claro con la posición de la que gozaron en la época colonial,

\section{LA RETÓRICA DE UNA IDENTIDAD NACIONAL ÚNICA}

Los nuevos Estados en Latinoamérica y el Caribe no sólo estuvicron en contra de la conciencia étnica que, iba surgiendo dentro de las fronteras del Estado, sino que también se sirvieron de esta conciencia para la construcción de una identidad nacional. Con el tiempo se corrió la voz de que distintos grupos étnicos podían mantener su propia identidad dentro del Estado, Esta voz fue propagada, en primer lugar, por los intelectuales (urbanos), después por los políticos y los funcionarios del Gobierno y más recientemente también por los medios de comunicación. Este enfoque de la etnicidad como parte de una 'identidad nacional' presenta distintas formas. En general, prácticamente siempre existió una contradicción entre, por una parte el objetivo del Gobierno de llegar a una ideología y cultura nacional homogénea y compartida unánimemente, y por otra parte el reconocimiento de la heterogencidad y consecuentemente del carácter local y grupal de la conciencia étnica.

Existe una línea divisoria relativamente clara entre los países en los que la diversidad étnica licne una importancia limitada - Argentina, Chile. Uruguay, $\mathrm{y}$ en parte México y Haití - y los países en los que la diferenciación étnica y los conflictos ćtnicos desempejiaron y a menudo todavía desempeñan un papel importante e incluso decisivo en la composición de una cultura "nacional". En el úllimo caso, a veces se proclamó una ideología étnica única 
como identidad nacional, con lo cual se negaron otras manifestaciones etnoculturales o éstas fueron consideradas como subculturas de segunda categoria. En otros casos, la propia diversidad étnica se convirtió en la característica principal de la identidad nacional.

En el Cono Sur, una ideologia de la homogeneidad énnica y la negación de las diferencias étnicas constituyeron las directrices en la formulación de la identidad nacional. En el caso de Chile, que tiene una población étnica casi homogénea, la etnicidad apenas influye en la vida diaria. La minoría india (aproximadamente el $5 \%$ de la población) vive predominantemente en la región meridional de Arauco. Sólo a finales del siglo XIX, las autoridades chilenas consiguieron someter mediante la violencia militar esta región (denominada de forma muy significativa la frontera) al Gobierno central. A la hora de construir una identidad nacional, que por lo demás está totalmente basada en el 'carácter europeo' de los chilenos, se difundió la contribución india a la nación chilena como un elemento predominantemente positivo. Los indios se convirtieron en el símbolo de la valentía, del orgullo y sobre todo de la indoblegabilidad del pucblo chileno. No es por nada que se les llama los indoblegables. Posteriormente, también influyó la formación relativamente rapida de un Estado fuerte con un alto grado de legitimidad y autoridad. Se propagó mucho la ideologia de la chilenidad - sobre todo a través de la enseíanza - cont lo cual la nacionalidad pudo funcionar como el elemento principal de la identificación. También el gran peso de las instituciones nacionales contribuyó a la propagación rápida de una idestidad nacional con un componente étnico lintitado.

Aunque, en gran medida es similar al caso chileno, el proceso argentino de la formación de naciones aporta algunas ideas adicionales. La immigración masiva europea eclipsó la estructura étnica, que se remontaba a la época colonial de este país muy poco poblado. El proceso de inmigración trazó nuevas líneas divisorias étnicas. Desde principios de este siglo, una nueva noción de la auténtica identidad argentina - con un carácter acentuadamente latino y católico - sustituyó al eurocentrisıno clásico de la élite intelectual. El origen curopeo ya no fue suliciente para poder integrarse al grupo élnico dominante. En las primeras décadas de este siglo incluso surgió una forma de "xenofobia? las víctimas de la misma no fueron negros e indios - como ocurrió en el resto del continente - que en este pais eran numéricamente insignificantes, sino grupos de inmigrantes blancos, La clite blanca argentina veía a los italianos, rusos y judios cono una amenaza potencial para la identidad nacional argentina. Los prejuicios (como el antiscmitisno) y el conservadurismo politico (el miedo a las ideas socialistas y anarquistas) se confundieron en este caso. Se buscó la solución en la asimilación cultural acelerada de los inmigrantes, principalmente 
a través de la enscrianza, quienes asi perderían su carácter subversivo y se integrarian en una cultura nacional homogénca.

Las socicdades con una heterogeneidad etnocultural mayor se enfrentaron a problemas mayores. Sus élites predominantemente blancas se vieron ante la tarea de crear una identidad nacional a partir de una gran diversidad énica. Esto parecía muy difícil, por no decir imposible - en parte debido a cllo el pesimismo cultural se convirtió en un rasgo tan característico de muchos intelectuales latinoamericanos. Pueblo enfermo, el libro que el boliviano Alcides Arguedas publicó en 1909, sólo es un ejemplo de la desesperación sentida con respecto a la suerte de la Latinoamérica étnicamente desgarrada. Autores como Arguedas reflejaron la lucha permanente con la propia identidad en la que la élite estaba implicada. Los dirigentes politicos a su vez impusieron, en lugar de reconocer la diversidad, una norma irrefulable a su sociedad, en la que predominaba la 'superioridad blanca', Esperaban en el futuro hacer desaparecer la diversidad étnica en sus sociedades con 'ingeniería étnica' ('ethnical engineering') en la enseñanza, con moralidad sexual y con una alimentación mejor.

En Brasil, para construir una identidad nacional se intentó relacionarse con la cultura 'occidental', es decir con la cultura 'blanca'. A partir del pesimismo cultural que acabamos de mencionar, se representó la diversidad étnica como un obstáculo para la realización del objetivo nacional. Por eso, a partir del último cuarto del siglo pasado, los intelectuales brasileños claboraron una seric de razonamientos ingeniosos para conciliar la 'triste' situación multiétnica del país con el ideal blanco.

En el Caribe de después de la Segunda Guerra Mundial la situación fue distinta. En paises predominantemente afro-caribeños como Jamaica, por to general se intentó crear una identidad nacional por medio de una ideología, en la que se enfrentaba a la población 'negra' con el colonialismo 'blanco'. En la época de la esclavitud las lineas divisorias entre blanco y negro, libre y esclavo, rico y pobre habian coincidido en su mayor parte. Tras la abolición de la esclavitud, la primera y la última contraposición permanecieron en gran medida intactas; en este caso, por lo general, la mayoria negra de la población identificaba el poder colonial con los intereses de la élite blanca local. El protonacionatismo del siglo XX en estas zonas unió el anticolonialismo y una conciencia negra articulada, y se enfrentó tanto a la metrópoli como a esas élites locales. Un ejemplo de antes de la Segunda Guerra Mundial es la Universal Negro Improvement Association del jamaicano Marcus Garvey. Después de Garvey, volveria a producirse con regularidad una revaloración de la propia herencia supucstamente africana, por ejemplo, en la ideología de los rastafarianos, que en tcoría aspiran a regresar al continente madre, Africa. 
En cstos movimientos negros de Afro-América resulta interesante, entre otras cosas, la utilización de un simbolismo africano - como ya se argumentó en el capítulo anterior con respecto a los marrones -, la enfatización de una herencia cuyos contornos son generalmente vagos y la evocación de un continente madre en su mayor parte imaginado. Estas construcciones han sido importantes ideológicamente, pero no tanto como directrices para la acción politica.

El problema de tales estrategias es que las poblaciones de la mayoria de los países no poseen una composición afro-americana homogénea. El Caribe espatiol, que por otra parte constituye númericamente la subregión más importante, forma con su población mulata y europea mucho más numerosa una categoria aparte. En la retórica moderna nacionalista, el enfoque se ha desplazado del núclco curopeo a conceptos como criollización y cultura mulata, aunque la cultura occidental y las élites blancas sigan siendo decisivas. La herencia 'africana' considerada originalmente como inferior ha experimentado una cierta emancipación, a la que, sin embargo, se han impuesto límites claros, que en parte coinciden con viejos sentimientos. Cuando los exiliados cubanos, refiriéndose a la crisis actual del pais y al aumento del porcentaje de negros en la población cubana en las últimas décadas, hablan de la 'haitianización' de Cuba, se evoca un mundo de diferenciación étnica que les une a una gran parte de las élites hispano-caribeñas, sin cxcluir a los fidelistas.

Por otra parte, el fomento de la berencia cultural afro-caribefia puede apoyar además de movimientos de conciencia étnica, también redes locales que se centran en objetivos concretos sociales o políticos. En este contexto, se puede entender, por ejemplo, el comportamiento reciente ambiguo del régimen de Fidel Castro con respecto a la santeria afro-cubana. - tomando las palabras de Marx - 'opio de una parte del pueblo', la santería es funcional para el régimen como calmante en una época de crisis económica y social. Además, la tolerancia de ese culto puede contribuir precisamente a que la numerosa población afro-cubana se vincule al régimen; en este sentido a Castro le resultó ventajoso abandonar las objeciones 'moralistas' anteriores en contra de una corriente etnorreligiosa considerada como retrasada e irracional. En cambio, la santería se está convirtiendo cada vez más en una red en la que se puede organizar la protesta social - y por ello para el régimen es alarmante el hecho de que cada vez más curo-cubanos vayan descubriendo este culto 'negro",

La situación más compleja se produjo en aquellos paises, en los que la historia colonial desembocó en sociedades extremadamente pluralistas en cuanto a la etnia. Donde más claramente se dio esa situación fue en Guyana, Trinidad y Surinam. En los dos países de las antiguas Indias Occidentales británicas existe una línea divisoria entre los habitantes de origen africano y los de origen 
británico-caribeño; por lo general varios grupos étnicos más pequeños actúan como mediadores. En Surinam, esta situación es aún más complicada debido a la existencia de una parte considerable de la población de origen javanés y debido al hecho de que la población afro-surinamesa se divide por una parte en 'criollos urbanos' y por otra en varios grupos de marrones. La división étnica de estas sociedades a menudo se puede comparar con la división ideológica de la sociedad holandesa antes de la Segunda Guerra Mundial, pero en realidad es más profunda. Así lo sienten también los gnupos de población involucrados. Se fortalece aun más la orientación hacia culturas y religiones dispares debido a una etnización de la economía y particularmente del mercado laboral. En este caso, el grado de mezcla interétnica es bajo, lo cual no hace sino mantener la división éfnica.

En estas sociedades pluralistas la etnicidad también desempeita un papel importante en el ámbito político. Asi, por ejemplo, en los países vecinos de Guyana y Surinam el grupo de población 'indostanesa' fue fiel durante décadas a un mismo dirigente político con carisma. Sin embargo, mientras que Cheddi Jagan de Guyana era un marxista declarado, el dirigente surinamés Jagernath Lachmon optó por una línca cautclosa, politicamente poco articulada. Las diferencias en la posición económica y las perspectivas de los grupos de población indostanesa en ambos países influyeron en la elección hecha por las bases de apoyo de ambos dirigentes. Sin embargo, la lealtad parece haber sido en primer lugar una cuestión de identificación con su 'propio' grupo étnico.

Sorprendentemente en estos paises no se han producido conflictos énioos abiertos; sólo en Guyana se dieron algunos periodos violentos. Sin embargo, las tensiones étnicas son endémicas y tienen tendencia a agravarse en épocas de crisis económica. Asi, parece ser que en Trinidad, país rico en petróleo y relativamente próspero en el pasado, la animosidad y el miedo a los disturbios étnicos han aumentado durante los últimos años proporcionalmente a la recesión de la economía.

En estas sociedades pluralistas la definición de una identidad nacional es muy dificil. La apuesta por la identidad africana, británico-caribeña o javanesa respectivamente tiene un efecto fragmentador en vez de fraternalizador. Por eso, después de la independencia la estabilidad politica de estas 'sociedades pluralistas' dependió en gran medida de la disposición y de la capacidad de las nucvas élites para subordinar el factor de la etnicidad en el proceso de formación de naciones. Alli donde éste no fue el caso, como en Guyana, las consecuencias fueron desastrosas. En general sólo hace falıa cxaminar el simbolismo de los lemas nacionales nuevamente inventados ('Out of Many One'. 'All o' We is One', "Wan Pipel'), de los himnos nacionales y de las banderas para hacerse 
una idea del carácter recientemente construido y por lo general débil del nacionalismo en las socicdades caribenas pluralistas.

\section{LA 'ASIMILACIÓN' DE LA DIVERSIDAD ÉTNICA}

Debido a los problemas mencionados anteriormente, los paises con una gran diversidad etnocultural intentaron, por lo general, adaptar una o ambas de las dos formas posibles de formación de la identidad nacional, que podemos llamar de orientación 'interna' y 'externa' respectivamente. La estrategia orientada hacia afuera se tratará en el siguiente apartado. En cl caso de la solución nacional 'interna', se intentó hacer de la necesidad virtud creando precisamente una 'cultura nacional' con un enfoque explícito en la heterogeneidad étnica. Asi en Cuba se alabó mucho la cultura mulata, en la cual la mezcla de razas y culturas pasó a ser la cualidad única de la cultura nacional. En otra parte del Caribe, se puede observar una evolución similar en la retórica en torno a la criollización y particularmente en los debates francocaribeños en torno a créolité y antillanité. Un ejemplo más antiguo constituye el México postrrevolucionario con la ideología 'hegemónica' de la cultura mestiza 'cósmica'.

Quizás Brasil ofrece el mejor ejemplo de la 'estrategia interna'. Desde la independencia, en la socicdad brasileña, la élite blanca dictaba la norma de la civilización europea blanca como esencia de la nación. Se adecuaron las tcorías raciales sobre la 'superioridad blanca' a la situación especifica de Brasil para así poder escapar a una forma demasiado fatalista de pesimismo cultural. Originalmente, como ya vimos, se partió de un proceso lento e ineludible de homogeneización élnica. La mezcla racial existente, la inmigración blanca y la idea singular de que los 'negros' sólo se podian reproducir con dificultad, despertaron en los intelectuales brasilcíos la esperanza de que con el tiempo la nación automáticamente iría perdiendo color, se haría 'blanca'.

Posteriormente, en el curso de los años 20 de este siglo surgió la famosa alternativa a estas idcas: la noción de la democracia racial. Sin embargo, la 'democracia racial' significaba también que otros grupos étnicos deberian renunciar a su carácter cultural para acceder a la cultura nacional brasileña. Hoy en día se comparten estas ideas en círculos amplios y en este sentido se pueden considerar como un intento logrado de formación de naciones. Esto no quita que también se haya recalcado el carácter encubridor de esta ideología 
nacional, es decir con vistas a marginar social y cconómicamente a la población indigena y afro-brasileña.

Además, actualmente se pide un mayor reconocimiento de la diversidad etnocultural de Brasil y de la ampliación del canon cultural nacional. Entretanto, efectivamente muchos elementos de la cultura 'no blanca' y en particular afrobrasileña han penetrado en el paradigma oficial de la brasildade. LLama la atención el hecho de que se hayan absorbido muchos elementos pintorescos y creativos principalmente de la cultura afro-brasileña en la construcción 'blanca' y clitista de la 'identidad nacional', a pesar de que la supremacia blanca no ha desaparecido ni metho menos. Los prejuicios, la discriminación y el dominio cultural no son sustituidos sin más por la magia del carnaval, la popularización de la música afro-brasileña o la religiosidad, o per la aceptación de la sensualidad mulata y de los símbolos sexuales como 'tipicamente' brasileños. Precisamente porque esos campos son menos amenazadores o incluso atractivos para la concepción oficial de la identidad nacional brasileña, resultan apropiados para reforzar la idea de la armonía ćtnica en el país.

Un ejemplo caribeño de un intento parecido de englobar la diversidad étnica bajo un denominador nacional común, se puede encontrar en Trinidad. En este país se introdujo el carnaval de origen criollo y afro-caribefio como 'vehículo' (Van Koningsbruggen 1993) en la construcción de una identidad nacional, que tendría que superar la gran escisión étnica de la socicdad. La sociedad de Trinidad consta de varios grupos étnicos, entre los cuales figuran dos grandes grupos de origen africano y británico-caribeño y grupos más pequeños de clinos, criollos blancos, etc. La clase media afro-trinitaria, que desde los años cincuenta ha ostentado casi continuamente el poder político, introdujo además de los símbolos locales del carnaval varios elementos comerciales norteamericanos. El ritual carnavalesco actual encaja en el proyecto del Gobierno, que tiene como objetivo por una parte crear una unidad nacional y englobar a todos los grupos étnicos bajo un nismo símbolo y por otra vender el pais en el extranjero, sobre todo con vistas al turismo, como un alegre melting pot étnico. Está claro que esta aspiración choca con la problemática cariberia de la sociedad pluralista señalada anteriormente.

\section{NACIONALISMO Y HOSTILIDAD ÉTNICA}

Una segunda estrategia para llegar a la construcción de una identidad nacional, a pesar de la he1erogeneidad énica de la propia población, es dirigir la atención hacia un enemigo étnico extranjero. Esta estrategia de carácter 
defensivo se ha aplicado con frecuencia en un contexto latinoamericano y caribeño. Normalmente iba dirigida contra Estados Unidos, un país al que se detestaba no sólo como gran potencia arrogante e imperialista, sino también como símbolo de un materialismo incivilizado. Tanto la derecha como la izquierda utilizó elementos de un nacionalismo antiyanqui con el fin de subrayar el carácter único de su propia sociedad. Además, los paises del Cono Sur, principalmente Argentina y Chile, tienden a recalcar su origen 'curopeo' frente al carácter indio primitivo de países como Perú y Bolivia, o frente al libertino carácter africano de Brasil.

El ejemplo clásico de una estrategia étnica nacional basada en la existencia de un enemigo exicrno se puede encontrar en la República Dominicana. Desde el punto de vista étnico, este país se sitúa entre el Caribe afro-americano y el continente latinoamericano mestizo. El idioma que se habla es el español, la población se siente estrechamentc vinculada a su origen español (verdadero o supuesto). Sin embargo, la cultura dominicana también se basa en elementos afro-americanos e incluso indios, y por supuesto en la interrelación entre esas culturas. Se parte de la base de que se puede calilicar al $70 \%$ de la población dominicana como mulata. Sin embargo, en este país se utiliza el término indio. Se puede considerar el simbolismo de esta terminologia como homólogo de la democracia racial brasileña. Hace mucho que la sociedad dominicana ya no tienc un carácter indio auténtico: la población india 'desaparecióo' de la isla poco después de la conquista española. Por eso, a veces se sugiere que el término indio se utiliza simplemente como referencia a los 'habitantes de América'. Es posible, pero sin embargo los dominicanos entre ellos mismos constantemente utilizan matizaciones como indio claro y indio oscuro. La utilización de este término parece sugerir una negación o una denigración implicita del elemento africano en la etnicidad dominicana.

Efectivamente, en la práctica las diferencias culturales y raciales apenas plantean problemas. En principio, todo el mundo tiene acceso a cualquier posición. Aunque todo el mundo es consciente de las diferencias somáticas, no influyen de forma demostrable en el trato social diario. En las relaciones politicas, la ctnicidad desempeña un papel más importante. Los dos grandes caudillos intelectuales y políticos de las últimas décadas. Joaquín Balaguer y Juan Bosch, son adversarios políticos declarados, pero como representantes de la élite política cosmopolita blanca se les puede considerar como representantes del mismo grupo dominante. A un candidato a presidente negro como Pería Gómez le está costando mucho que la élite política de la República Dominicana le acepte. Frecuentemente se le echa en cara que no es un dominicano, porque su madre es haitiana.

En este dato, que a primera vista parece insignificante, radica la esencia

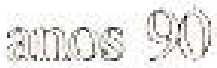


de la relación entre etnicidad y nacionalismo en la República Dominicana. En la construcción del nacionalismo dominicano, poco a poco el país vecino Haití se ha convertido en el símbolo del primitivismo afro-americano. No resulta difícil saber cuál es el origen de esta imagen hostil. En primer lugar se encuentra en la historia. Haiti surgió como un Estado de esclavos negros liberados. A la élite blanca de la parte española de la isla le prcocupaba mucho lo que estaba ocurriendo en el país vecino. No tanto porque ellos mismos tenían esclavos, sino más bien porque se identificaban con las ideas europeas de los dirigentes políticos franceses ahuyentados. Además, en el siglo XIX los haitianos invadieron varias veces la República Dominicana. Durante 22 años (18221844), Hailí incluso ocupó el pais vecino, aunque hay que tener en cuenta a este respecto que las intervenciones haitianas contaron a menudo con el apoyo de grupos de la sociedad dominicana.

El hecho de que estos prejuicios perduraran e incluso se reforzaran en el siglo XX se debe en gran parte al atraso económico de Hailí. En la primera mitad del siglo XX. esto tuvo como consecuencia una gran afluencia de immigrantes haitianos que se pusieron a trabajar como asalariados en las plantaciones de azúcar dominicanas. Bajo la dictadura de Rafael Trujillo (19301961), las autoridades hicieron todo lo posible por avivar la aversión por los haitianos, entre otras cosas, presentándoles como los culpables de que los dominicanos no pudieran ganarse la vida honradamente. El triste desenlace de esta campaña fue el asesinato de más de 10.000 haitianos por parte de los militares dominicanos en 1937.

En la República Dominicana actual, todos los sectores de la cconomía se sirven de la mano de obra haitiana para realizar los trabajos peores por un salario de miseria. Un ejemplo tipico del razonamiento circular propio de estos prejuicios étnicos es que los haitianos se ven obligados a aceptar por necesidad unas condiciones de vida inhumanas. En el debate público se utiliza la aceplación de estas condiciones como argumento para resaltar la rudeza de los haitianos.

Por tanto, los prejuicios raciales en la República Dominicana no se enfocan en la situación interna, como ocurre en Brasil, sino casi exclusivamente cn el 'peligro' extranjero, Los prejuicios contra los 'negros' se centran en los habitantes del pais vecino Haiti. La manipulación idcológica llevada a cabo por la ćlite la contribuido en gran medida a cllo. Sin embargo, resulta demasiado fácil decir que se trata únicamente de la manipulación de la opinión pública dominicana. Aunque es imposible averiguar con exactitud las causas de los prejuicios dominicanos, se debe considerar el antihaitianismo como una parte integral de la cultura dominicana. En amplios sectores de la sociedad, tanto en el campo como en la ciudad, tanto entre los de izquierdas como entre los de 
derechas. existen prejuicios raciales en contra de los haitianos, que sobre todo están relacionados con su bajo nivel de espafiol y su falta de cultura, con su primitivismo (el vudú sería una prucba de ello) y su falta de higiene (actualmente asociada con el SIDA). En este momento estas ideas no parecen servir a un objetivo politico o social concreto. Sin embargo, en cl pasado estas ideas fueron manipuladas con frecuencia por la élite política e intelectual con el fin de reforzar un sentimiento de identidad nacional propia. Por eso, aparentemente los prejuicios en contra de los laitianos pueden activarse en cualquier momento.

En general, se puede afirmar que los Estados modernos consideran la enfatización de las diferencias étnicas dentro de las fronteras de sus paises como una cuestión muy peligrosa. Allí donde pueden, intentan neutralizar, ocultar o incluso reprimir la diversidad étnica. For el contrario, en las relaciones con el mundo exterior a menudo se exageran mucho las diferencias etnoculturales. El antagonismo así creado contribuye a promover una unidad nacional y quita importancia a los posibles contrastes étnicos internos.

\section{CONCLUSIÓN}

En la historia reciente de Latinoamérica la relación entre formación de naciones y etnicidad ha sido muy compleja. Los cjemplos citados dan prucba de una tensión continua entre la aceptación de las diferencias étnicas y los esfuerzos por incorporar la pluralidad étnica en el Estado nacional por una parte y por otra por negar y reprimir las etnicidades especílicas.

En general se puede observar que, por lo menos en el ámbito político, las diferencias somáticas tuvieron y tienen menos importancia que las diferencias socioeconómicas y culturales. Además, no hubo un "protonacionalismo étnico' y sólo durante la formación de maciones las diferencias se actualizaron como un tema de definición, conflicto y negociación. En un principio, los dirigentes de los nuevos Estados latinoamericanos defendieron los 'intereses de la clase criolla' frente a la injerencia desde Madrid y Lisboa. Sin enbargo, en primer instancia, el provincialismo y el miedo a la rebelión, tanto de los esclavos como de los indios, contra el orden establecido prevalecieron sobre las nociones de por si ya ambivalentes sobre una identidad (pan)americana. Debido al 'fantasma' de Haití perduró esta actitud hasta principios del siglo XX y tuvo como consecuencia que la independencia de Hispanoanérica y, en menor grado, la de Brasil, se consolidase en base al modelo 'civil' de formación de naciones y que en gran parte se canalizase dentro de los parámetros de la división administrativa colonial. 
A raiz de la heterogeneidad etnocultural y el eurocentrismo también étnico de las élites, el problema principal del siglo XIX fue la incorporación civil y la asimilación cultural de las 'clases, castas y esclavos'. Sólo a partir de 1870 aproximadamente, cuando los nuevos Estados se habían consolidado más o menos, se empezó a aspirar de forna consciente a la homogeneización étnica. No obstante, la norma siguió siendo una etnicidad definida a la 'europea'. Las cstrategias utilizadas variaron también según el grado de heterogencidad étnica de las sociedades involucradas. En países como México y Brasil, el abismo entre la élite europea y la población 'india' y negra respectivamente funcionó como la línea divisoria social relevante, mientras que en el Cono Sur lo que fue relevante fue la diferenciación étnica entre los distintos grupos de población europea.

La cuestión de la incorporación y de la plena ciudadanía de todos los grupos étnicos siguió dominando los procesos de formación de naciones en el siglo XX. Cada vez se negaron menos la diversidad étnica y el mestizaje y pasaron a formar parte precisamente de los cálculos políticos y de las filosofías sociales y morales. Conceptos como mestizaje y democracia racial pasaron a ocupar un lugar central en la retórica nacionalista, aunque a menudo en la práclica fue distinto. Esłe cambio permitió que se manifestaran las estrategias étnicas de los grupos que anteriormente fueron catalogados como 'inferiores'. Los grupos de población afro-americana en las sociedades dominadas por 'blancos"se centraron principalmente en conseguir unos derechos civiles plenos, mientras que los grupos indios intentaron además alcanzar cierta autonomía ètuica.

En los últimos años, un creciente número de grupos indigenas han descubierto el gran potencial político que posec la combinación de la noción de 'identidad primordial' con una de 'derechos originales'. De esta manera, en la actualidad se pueden identificar diversos grupos indigenas que invocan a la supuesta existencia de sus raices precolombinas para alimentar estrategias que van dirigidas a la obtención de recursos fundamentales, tales como el acceso a la tierra, la conducción de la administración local, y el fortalecimiento de la identidad cultural. Dicha invocación a supuestos 'derechos primordiales' hacer suponer, en principio, que esta estrategia tiende a disvincularse de las instituciones del Estado existentes. En particular, a lo que respecta al inherente componente territorial que posee esta aspiración que resultaria incompatible con la naturaleza misma del Estado nacional moderno. No obstante, y a menudo tras largas décadas de confrontación y violencia, se ha llegado en algunos paises a compromisos en los cuales se refleja el principio de la existencia de una nación multicultural o incluso de un Estado multinacional. De todo ésto queda en evidencia que el éxito de estas estrategias indigenas dirigidas a la 
obtención de un mayor grado de autonomia depende, al mismo tiempo, de la consolidación de Estados nacionales soberanos. Así, los arreglos negociados con Estados (o gobiernos) fuertes, legítimos y democráticos constituye una condición fundamental para el logro de la ansiada autonomía étnica.

En vista de lo anterior no resulta sorprendente el surgimiento de organizaciones indigenas a nivel nacional que funcionan como vehículos de tas estrategias dirigidas a la ampliación de la ciudadanía. Dichas estrategias proveen de bases politicas y legales a la definición de intereses especificos, sustentados en una identidad cultural. Es por ésto que dudamos que en el caso latinoamericano la adopción de un etno-nacionalismo de carácter separatista, como se ha dado en otras regiones del mundo (Europa oriental, en el Caucaso y en Asia central y meridional) posea un verdadero potencial transformador,

La cuestión de la identidad nacional siguió siendo un tema de debate. A veces, las estralegias asertivas que proyectaron imágenes hostiles étnicas hacia afuera se sirvieron sobre todo de una retórica unificadora con respecto al propio carácter étnico-nacional. En un sentido más amplio, en la aspiración a una identidad nacional de lo más englobadora posible, el énfasis en una negación de las diferencias étnicas o en una enfatización de una jerarquia étnica se fue sustituyendo por una retórica de 'criollización' y mestizaje. En este caso, dejando a un lado los efectos internos, también se trata de un enfoque 'exotizador' consciente. con el cual los países latinoamericanos y caribeños modernos se presentan en el 'concierto de las naciones' con voz propia.

\section{BIBLIOGRAFÍA}

Allen, Elizabeth (1989) 'Brazil: Indians and the New Constitution', Third World Quarterly 11(4): 148-65.

Anderson, Benedict (1992) Imagined Communisies: Reflections on the Origins and Spread of Nationalism. Londres: Cambridge University Press. [1983]

Andrews, George Reid (1988) 'Black and White Workers: Săo Paulo, Brazil, 1888-1928', Hispanic American Historical Review 68(3): 491-524.

Banck, Geert A. (1990) 'Poder e Identidade; reflexâo sobre a cultura nacional'. Ciencia e Cullura 42: 1073-81.

Barman, Roderick, J. (1988) Brazil: the Forging of a Nation, 1798-1852. Stanford: Stanford University Press.

Barre, Marie-Chantal (1984) 'Mexique: une Nouvelle Politique Indigeniste'. Amerrique latine 17: 25-30. 
Barth, Fredrik (comp.) (1969) Ethnic Groups and Boundaries: The Social Organization of Cultural Differences. Londres: Allen \& Unwin.

Baud, Michiel (1992) 'Sugar and Unfree Labour: Reflections on Labour Control in the Dominican Republic, 1870-1935', Journal of Peasant Studies 19: $302-25$.

Bengoa, José (1985) Ifistoria del pueblo Mapuche. Santiago de Chile: Ediciones Sur.

(1986) 'Sociedad criolla, sociedad indígena y mestizaje en Chile', Proposiciones 6(12): 119-20.

(1992) 'The Mapuche Peasants under the Military Regime', en Cristóbal Kay y Patricio Silva (comps.), Development and Social Change in the Chilean Countryside, pp. 233-45. Ansterdam: CEDLA.

Bentley, G, Carter (1987) 'Elhnicity and Practice', Comparative Siudies in Society and History 29(1): 24-55.

Bonfil Batalla, Guillermo (1981) Utopia y revolución. El pensamiento politico contemporaneo de los indios en América latina. Mexico: Ed. Nueva Imagen.

Borges, Dain (1993) "«Puffy, Ugly, Slothful and Inert»: Degeneration in Brazilian Social Thought, 1880-1940, Journal of Latin American Studies 25: $235-56$.

Bourgois, Philippe I. (1981) 'Class, Ethnicity and the State Among the Miskilu Amerindians of Northeastern Nicaragua', Latin American Perspectives $8(2)$ : 22-39, (1989) Ethnicity at Work: Divided Labor on a Central American Banana Plantation. Baltimore y Londres: The Johns Hopkins University Press.

Burton, Richard (1993) ' Ki Moun Nou Ye? The Idea of Difference in Contemporary French West Indian Thought', New West Indian Guide/ Nieuwe Hest-Indische (iids 67: 5-32.

Carmack, Robert M. (comp.) (1991) Guatemala: Cosecha de Violencias. San José: FLACSO.

Cunla. Euclides da (1983) Os Seriōes. Porto: Lello \& Irmão. [1901]

Demelas, M.D. (1981), 'Darwinismo a to criollo. El darwinismo social en Bolivia, 1880-1910'. Historia boliviana 1 (2): 55-82.

Drescher, Seymour (1988) 'Brazilian Abolition in Comparative Perspective', Hispanic American Historical Review 68: 429-60.

Dunbar Ortiz, Roxanne (1987) 'Indigenous Rights and Regional Autonomy in Revolutionary Nicaragua', Latin American Perspectives 14(1): 43-66.

Fennema, Meindert y Troctje Locwenthal (1987) Construcción de raza y nación en República Dominicana. Santo Domingo: Editorial Taller. 
Fernandes, Florestan (1969) The Negro in Brazilian Society. Nueva York: Columbia University Press. [1965]

Freeland, Jane (1989) 'Nationalist Revolution and Ethnic Rights: the Miskitu of Nicaragua's Atlantic Coast', Third World Quarterly 11(4): 166-90.

Freyre, Gilberto (198) New World in the Tropics. The Culture of Modern Brazil. Westport: Grecnwood (1945) The Masters and the Slaves. A Study in the Development of Brazilian Civilization. Berkeley: University of California Press. [1933]

Gellner, Ernest (1992) Nations and Nationalism. Oxford: Blackwell, [1983]

Graham. Richard (comp.) (1990) The Idea of Race in Latin America, 18701940. Austin: University of Texas Press.

Guideri, R, F, Pellizzi y J. Tambiah (comps.) (1988) Ethnicities and Nations. Processes of Interethnic Relations in Latin America. Southeast Asia and the Pacific. Austin: University of Texas Press,

Hasenbalg, Carlos, A. (1979) Discriminaçao e Desigualdades Raciaisno Brasil. Rio de Janciro: Graal.

Helg, Aline (1990) 'Race in Argentina and Cuba, 1880-1930: Theory, Politics and Popular Reaction', en R. Graham (comp.). The Idea of Race in Latin America, 1870-1940, pp. 37-70. Austin: University of Texas Press.

Hendricks, Janet (1991) 'Symbolic Counterhegemony among the Ecuadorian Shuar', en G. Urban y J. Sherzer (comps.), Nation-Siates and Indians in Latin America, pp. 53-71. Austin: University of Texas Press

Hobsbawm, Eric J. (1991) Nations and Nationalism Since 1780: Programme, Myth, Reality. Cambridge: Cambridge University Press.

Kuight. Alan (1990) 'Racism, Revolution, and indigenismo: Mexico, 19101940', en R. Grahan (comp.), The Idea of Race in Latin America, 1870 1940. pp. 71.114 . Austim: University of Texas Press.

Hasenbalg, Carlos (1994), 'Perspectivas sobre raza y clase en Brasil', Esiudios sociológicos, 34; 75-99.

Knight, Franklin W. (1990) The Caribbean: Genesis of a Fragmented Nationalism. Nucva York: Oxford University Press.

Koningsbruggen, Peter van (1993) /let carnaval van Trinidad. Wertuig in de speurtocht natr nationale identiteit. Utrecht: ISOR.

Levine, Robert M. (1988) '«Mud-Hut Jenusalem»; Canudos Revisited', Hispanic American /istorical Review 68: 525-72.

Leys Stepan, Nancy (1992) 'The Hour of Eugenics', Race, Gender, and Nation in Latin America. Ithaca y Londres: Cornell University Press.

Maingot, Anthony (1996) 'Haiti and the Terrified Consciousness of the Caribbean in the 19th Century: Implications for the 21st Century', en Gert Oostindic (comp.). Ethnicity in the Caribbean. Londres: Macmillan. 
Mallon, Florencia (1992) 'Indian Communities, Political Cultures and the State in Latin America, 1780-1990', Joumal of Latin American Studies 24:3554.

Moore, Carlos (1988) Castro, the Blacks, and Africa. Los Angeles: Center for Afro-American Studies, UCLA.

Nicholls, David (1979) From Dessalines to Duvalier: Race, Colour and National Independence in Haiti. Cambridge: Cambridge University Press.

Oliven, Ruben G. (1986) Volencia e Cultura no Brasil. Petrópolis: Vozes.

Palmer, David Scott (comp.) (1992) The Shining Path of Peru. Londres: Hurst.

Pérez, Louis, A. (1986) 'Politics. Peasants and Pcople of Color: The 1912 «Race War» in Cuba Reconsidered', Hispanic American Historical Review 66: $509-39$.

Portes, Alcjandro (1985) 'Latin American Class Structures: Their Composition and Clange during the Last Decades', Latin American Research Review 20(3): $7-39$.

Saflord, Frank (1991) 'Race, Integration and Progress: Elite Attitudes and the Indian in Colonbia, 1750-1870', Hispanic American Historical Review $71: 1-33$.

Schwarcz. Lilia Moritz (1993) O espetáculo das raças. Cientistas, instituiçōes e questão racial no Brasil, 1870-1930. Säo Paulo: Companhia Das Letras.

Silva, Patricio (1993) 'State, Politics and the Idea of Social Justice in Chile', Development and Change 24: 465-85.

Skidmore, Thomas, E. (1983) 'Race and Class in Brazil: Historical Perspectives', Laso-Brazilian Review 20(1): 104-18,

(1990) 'Racial Ideas and Social Policy in Brazil, 1870-1940', en Richard Graham (comp.). The Jdea of Race in Latin America, 1870-1940, pp. 7-36. Austin: University of Texas Press.

Suith, Anthony D. (1981) The Ethnic Revival. Cambridge: Cambridge University Press.

(1986) The Ethnic Origins of Nations. Nueva York: Basil Blackwell.

Tilly, Charles (1990) Coercion, Capital, and European States, AD 990-1990. Oxford: Basil Blackwell.

Torres Rivas, Edelberto (1988) 'La Nación: problemas teóricos e históricos'. en Norbert Lechner (comp.), Estado y Politica en América Latina, pp. 87132. Ciudad de México: Siglo XXI.

Touraine, Alain (1989) América Latina: politica y sociedad. Madrid: Espasa Calpe.

Urban, Greg (1985) 'Developments in the Situation of Brazilian Tribal 
Populations from 1976 to 1982', Latin American Research Review 20(1): $7-25$,

Urban, Greg en Joel Sherzer (comps.) (1991) Nation-States and Indians in Latin America. Austin: University of Texas Press.

Vilas, Carlos, M. (1989) State, Class and Ethnicity in Nicaragua. Capitalist Modernization and Revolutionary Change on the Allantic Coast. Boulder y Londres: Lyme Reinner.

Viotti da Costa, Emilia (1985) The Brazilian Empire: Myths and Histories. Chicago y Londres: Chicago University Press.

Williams, Brackette F. (1991) Stains on My Name, Har in My Veins, Guyana and the Politics of Polifical Siruggle. Durham: Duke University Press.

Winant. Howard (1992) 'Rethinking Race in Brazil', Joumal of Latin American Srudies 24(1): 173-92.

Zimmerman, Eduardo, A. (1992) Racial ldeas and Social Reforms: Argentina, 1890-1916' //ispanic American Historical Review 72: 23-46. 


\section{DISTRAERSE EN BUENOS AIRES: perfiles sociales y prácticas culturales en los cafés y despa- chos de bebidas, $1860-1910$}

Sandra GAYOL*

Frecuentar el café es una práctica social profundamente arraigada en la cultura argentina. Existe incluso en nuestro vocabulario un verbo, cafetear, para designar exta extendida actividad social. Si hoy es imposible transitar por una ciudad como la de Buenos Aires sin toparse con estos espacios de sociabilidad, cien años antes la situación no era diferente. En la segunda mi

tad del siglo XXX en una Buenos Aires que expande sus fronteras ( $)$, muliplica y diversifica su componente poblacional ( ), y es sacudida por un proceso "modernizador"; los cafes no permanecen al margen al converfirse en cajas de resonancia de las transformaciones urbanas.

La participación activa de los despachos de bebidas () ) en la fisonomia de la ciudad es facil de establecer en la medida que cierran, abren, dividen una calle, definen la morfologia de la "zona céntrica" yestán a la vanguardia de un asentamienio urbano ('). Diseminados en el espacio de la ciudad, caracteristicos del Buenos Aires de fines de siglo; son centrales para los cientos de hombres que se inyectan cotidianamente en su interior.

Por qué ir al café? Cómo explicar el becho que están incorporados a la vida de los hombres de la ciudad? Primero que nada: quićnes iban a los despachos de bebidas, en qué momento y para hacer qué? En las páginas que siguen intentaremos responder a estas preguntas para el periodo comprendido entre 1860-1910, buscando primeramente desbrozar los rostros de la clientela a partir de sus datos de filiación, Luego veremos los ritmos de frecuentación y ciertas condiciones y prácticas sociales que pueden ayudarnos a entender las razones por las que para muclıos hombres su vida es casi inseparable del café.

Los partes diarios de la policia y los tesimonios de sentencia de la

*IEHS-l Inícen-Conio: 